Atmos. Chem. Phys., 18, 12161-12184, 2018

https://doi.org/10.5194/acp-18-12161-2018

(c) Author(s) 2018. This work is distributed under

the Creative Commons Attribution 4.0 License.

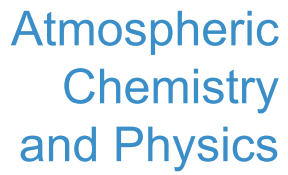

(c) (P)

\title{
Investigating the impacts of Saharan dust on tropical deep convection using spectral bin microphysics
}

\author{
Matthew Gibbons ${ }^{1}$, Qilong Min ${ }^{1}$, and Jiwen Fan ${ }^{2}$ \\ ${ }^{1}$ Atmospheric Science Research Center, State University of New York, Albany NY 12203, USA \\ ${ }^{2}$ Earth Systems Analysis and Modeling, Pacific Northwest National Laboratory, Richland WA 99352, USA
}

Correspondence: Qilong Min (qmin@albany.edu)

Received: 30 June 2017 - Discussion started: 30 August 2017

Revised: 23 March 2018 - Accepted: 23 March 2018 - Published: 23 August 2018

\begin{abstract}
To better understand the impacts of dust aerosols on deep convective cloud (DCC) systems reported by previous observational studies, a case study in the tropical eastern Atlantic was investigated using the Weather Research and Forecasting (WRF) model coupled with a spectral bin microphysics (SBM) model. A detailed set of ice nucleation parameterizations linking ice formation with aerosol particles has been implemented in the SBM. Increasing ice nuclei (IN) concentration in the dust cases results in the formation of more numerous small ice particles in the heterogeneous nucleation regime (between -5 and $-38^{\circ} \mathrm{C}$ ) compared to the background ("Clean") case. Convective updrafts are invigorated by increased latent heat release due to depositional growth and riming of these more numerous particles, which results in increased overshooting and higher convective core top heights. Competition between the more numerous particles for available water vapor during diffusional growth and available smaller crystals and/or drops during collection reduces particle growth rates and shifts precipitation formation to higher altitudes in the heterogeneous nucleation regime. A greater number of large snow particles form in the dust cases, which are transported from the core into the stratiform regime and sediment out quickly. Together with reduced homogeneous ice formation, the stratiform and/or anvil cloud occurrence shifts frequency to warmer temperatures and reduces anvil cloud extents. Total surface precipitation accumulation is reduced proportionally as IN concentration is increased; though the stratiform precipitation accumulation is increased due to greater snow formation and growth, it does not counteract the reduced convective accumulation due to less efficient graupel formation. Radar reflectivity values are increased in the dust cases at temperatures below $0^{\circ} \mathrm{C}$ in both
\end{abstract}

the convective and stratiform regimes due to more large snow particles, and reduced in the convective core near the surface due to melt of small ice or graupel particles, consistent with case study observations.

\section{Introduction}

Deep convective clouds (DCCs) are important sources of precipitation and play a strong role in both regional and global circulation, with tropical convection being particularly significant (Arakawa, 2004). The strong updrafts within convective clouds can transport small cloud particles to the level of neutral buoyancy where they spread out to form the anvil cloud associated with DCC (Folkins, 2002; Mullendore, 2005). Convective intensity is the primary determiner of the depth, area, and lifetime of the resulting anvil clouds (Futyan and Del Genio, 2007). However, observational and numerical studies of aerosol indirect effects (AIEs) suggest that changes to cloud microphysical processes can significantly modulate these macrophysical qualities (Fan et al., 2007, 2010a, 2013; Min et al., 2009; Koren et al., 2010a, b; Li et al., 2011; Niu and Li, 2012; Storer et al., 2014; Saleeby et al., 2016). AIE on shallow clouds has been extensively studied in the past, as noted in the review by Fan et al. (2016), but additional research on AIE within deep clouds is still needed. The greater area coverage and lifetime persistence of the anvil cloud compared to the convective core makes the anvil cloud, and any changes resulting from AIE, important to global energy balance and radiative transfer. This makes the study of DCC important for current and future climate research (Solomon et al., 2007; Rosenfeld et al., 2013). 
Dust aerosols have been observed at significant concentrations even in remote locations far from their expected source regions (Prospero, 1999). They are predominately composed of insoluble silicate particles (Lohmann, 2002), which have been established to act as effective ice nuclei (IN, Pruppacher and Klett, 1997; DeMott et al., 2003; Sassen et al., 2003; Boose et al., 2016) and/or cloud condensation nuclei (CCN; Twohy et al., 2009; Kumar et al., 2011; Karydis et al., 2013). The Saharan air layer (SAL; Prospero and Carlson, 1970; Carlson and Prospero, 1972) is an elevated layer of dry air between 850 and $500 \mathrm{hPa}$, often containing lofted dust particles. The SAL has been observed interacting with tropical cloud systems, such as tropical cyclones and mesoscale convective systems (MCSs), and may impact their intensity and evolution (Karyampudi and Carlson, 1988; Dunion and Velden, 2004; Evan et al., 2006; Min et al., 2009; Zhang et al., 2009; Braun, 2010; Lau et al., 2010; Carrio and Cotton, 2011; Cotton et al., 2012; Braun et al., 2013). A trans-Atlantic dust outbreak of Saharan origin occurring 1-10 March 2004 (Morris et al., 2006) was subjected to a rigorous multi-sensor and multi-platform observational analysis (Min et al., 2009, 2014; Li et al., 2010; Min and Li, 2010; Li and Min, 2010). The interaction of this dust outbreak with a well-developed MCS resulted in strong effects on cloud microphysical processes. Small ice particles were abundant in the heterogeneous nucleation regime in the dusty region. The size spectrum of the vertical precipitation structures was shifted from heavy to light precipitation (Min et al., 2009; Li and Min, 2010). Substantial changes to cloud top distributions and precipitation profiles resulted from a change in the partition between homogeneous and heterogeneous ice formation processes under dusty conditions. Such macrophysical changes in the cloud systems resulted in substantial thermal infrared radiation cooling of up to $16 \mathrm{~W} \mathrm{~m}^{-2}$ (Min and $\mathrm{Li}, 2010$ ). The reported changes to cloud top distribution and the partition between homogeneous and heterogeneous ice formation differ from those described by studies focusing on the $\mathrm{CCN}$ activation of aerosols, suggesting that IN activation of dust was a significant contributor to the observed differences in the MCS.

Observational and modeling studies of DCC have shown different results relating to the effect of aerosol on convection and precipitation, indicating that aerosol may either enhance or suppress convection and precipitation depending on aerosol concentration and environmental conditions (Khain and Pokrovsky, 2004; Khain et al., 2004, 2005, 2008; van den Heever et al., 2006; Fan et al., 2007; Lee et al., 2008; Min et al., 2009; Min and Li, 2010; Li and Min, 2010; Min et al., 2014; Altaratz et al., 2014). Clouds forming in elevated aerosol environments exhibit reduced cloud drop effective radii as a result of a greater number of smaller drops forming (Andreae et al., 2004; Koren et al., 2005). This can result in less efficient collision-coalescence processes (Khain et al., 2005), which shifts the formation of precipitation to higher altitudes in the clouds. Condensation and evaporation pro- cesses are affected by the altered drop size distribution and number concentration, resulting in changes to the location and intensity of latent heat release within the cloud (Khain et al., 2005; Rosenfeld et al., 2008). The higher droplet concentrations induce greater condensation and latent heat release, resulting in stronger convective updrafts and the formation of taller and wider clouds (Frederick, 2006; Zhang et al., 2007). Increased evaporation of smaller drops can result in stronger cold pool formation and enhanced secondary convection, and such increased evaporation at the cloud periphery under polluted conditions can also increase the mixing between the cloud and the environment (Khain, 2009; Lee et al., 2010). Conversely, other studies have noted that the formation of larger drops due to enhanced rain drop collision-coalescence limits evaporation and weakens the cold pool (Altaratz et al., 2008; Berg et al., 2008; Lerach et al., 2008; Storer et al., 2010; Lim et al., 2011; May et al., 2011; Morrison, 2012; Grant and Van Den Heever, 2015).

Changes in large-scale cloud geometry that are related to aerosol indirect effects are frequently attributed solely to thermodynamical invigoration as a result of increased liquid and/or ice particle number concentrations and subsequent changes to diffusional growth processes in the convective regime. However, modeling studies have suggested that thermodynamic invigoration can be insignificant or even suppressed for clouds with a cold base or for clouds developing in a dry and/or high wind shear environment (Fan et al., 2009, 2012b, 2013; Lee et al., 2008; Khain et al., 2005, 2008; Tao et al., 2007; Lebo et al., 2012; Lebo and Seinfeld, 2011). However, a study by Fan et al. (2013) involving simulations of DCC in three different regions suggested that the observed taller and wider clouds could be better explained by changes to microphysical properties such as the particle size distribution. The study noted that thermodynamic invigoration resulting from increased latent heat release did not unanimously occur in the study when polluted conditions were simulated, although increased cloud fraction and cloud top height were present. The study noted that the reduced hydrometeor sizes in the polluted case allowed greater cloud mass to be detrained from the convective core and decreased particle fallout speed that slows down the cloud anvil dissipation.

Earlier numerical studies of aerosol-cloud interactions tend to focus upon the action of soluble aerosols such as $\mathrm{CCN}$, with changes to ice formation resulting from the affected liquid processes only (Khain et al., 2005; Fan et al., 2009b, 2012a, b; Storer and van den Heever, 2013; Saleeby et al., 2016). However, DCC can also be sensitive to the aerosols that act as IN (Van den Heever et al., 2006; Ekman et al., 2007; Tao et al., 2012). The study of Van den Heever et al. (2006) described the differing impacts of CCN and IN on convective clouds and subsequent anvil development. They found that increasing $\mathrm{CCN}$ concentration tended to reduce surface precipitation. Increasing IN concentration initially increased surface precipitation, but eventually re- 
duced the total to less than the control case by the end of the simulation. Updraft intensity increased with the increased aerosol concentration due to stronger latent heat release, but anvils were generally smaller and more organized. Ekman et al. (2007) studied the sensitivity of a continental storm to IN concentration and found that updrafts were enhanced due to added latent heat release from ice crystal depositional growth. The stronger updrafts enhanced homogeneous nucleation, increasing anvil cloud coverage and precipitation. Fan et al. (2010a) compared the effects of CCN and IN on convection and precipitation and noted that the CCN effect is more evident in changing cloud anvil size, lifetime, and microphysical properties. IN was shown to have a small effect on convective strength, but the microphysical effects could still be significant. However, it should be noted that Fan et al. (2010a) did not have a prognostic IN treatment as what we have done for this study.

Aerosols such as dust influence the character of individual clouds and storms, but evidence of a systematic effect on storm or precipitation intensity is still limited and ambiguous. Therefore detailed numerical models are required to understand the dynamical and microphysical changes that result in the observed effects of dust on DCC. However, the representation of DCC processes relevant to aerosol-cloud interactions is still considered weak, due to some of the fundamental details of cloud microphysical processes still being poorly understood. This is particularly true with regards to ice and mixed-phase clouds (Boucher et al., 2013). This low confidence is a result of the complex coupling between the processes controlling cloud and precipitation properties, which cover a wide range of spatial and temporal scales (Tao et al., 2012). Large uncertainties also exist in ice nucleation parameterizations within numerical models (DeMott et al., 2010). However, comparison of model results with a wellobserved case study, such as the multi-platform and multisensor Min et al. (2009) study, can limit the impact of these uncertainties when analyzing results from numerical simulations. Ice formation in DCCs may result from heterogeneous and/or homogeneous ice nucleation depending on the depth of the cloud and the chemical composition of the background aerosols. Heterogeneous ice nucleation can occur at temperatures between -5 and $-38^{\circ} \mathrm{C}$ via the mechanisms of deposition, immersion, and contact freezing (Vali et al., 1985, 2015) when ice nuclei (IN) are present. Homogeneous ice nucleation involves droplet and aerosol haze particle freezing at temperatures lower than $-38^{\circ} \mathrm{C}$ (Koop et al., 2000; Möhler et al., 2003; Ren and MacKenzie, 2005). Deep convection frequently shoots liquid drops up to the upper troposphere where the temperature is colder than $-38^{\circ} \mathrm{C}$, leading to strong homogenous droplet freezing. Therefore, a comprehensive handling of both heterogeneous and homogeneous ice formation mechanisms must be incorporated into numerical simulations to gain a clearer understanding of ice formation in DCC.
Observations suggest that the presence of IN particles such as dust has a significant impact on the microphysical and macrophysical properties of DCC, but many numerical simulations rely on a relatively simple handling of IN particles and the associated heterogeneous ice formation mechanisms. Accurate simulations of ice formation processes in DCC require ice nucleation to be directly linked with IN concentration. In this study, we add a prognostic IN variable to allow for the transport of IN particles by the wind field and the removal of IN by heterogeneous ice formation. We also update the set of heterogeneous and homogenous ice nucleation parameterizations within the WRF-SBM to connect ice nucleation with dust particles. Heterogeneous ice formation resulting from the updated immersion, contact, and deposition-condensation freezing schemes account for the full range of ice formation mechanisms active at temperatures between -5 and $-38^{\circ} \mathrm{C}$. Detailed information on specific updates made to the model has been provided in Sect. 2 . We simulate the observed MCS occurring on 8 March 2004 in the tropical eastern Atlantic under background ("Clean") and dust-affected conditions. The Clean case will be used as a baseline to evaluate the model's skill at reproducing the observed cloud and precipitation fields of DCC not affected by the observed dust outbreak. The dust cases will test the sensitivity of the baseline case to different number concentrations of IN. Comparing the changes experienced by the dust cases with observations will allow us to test the sensitivity of various ice formation mechanisms within the MCS to the presence of dust and verify the hypotheses of Min et al. (2009) and the later associated studies. Radar reflectivity measurements provide a valuable insight into the microphysical impacts of aerosols, such as dust, on DCC when analyzed in conjunction with detailed numerical simulation results. However, radar reflectivity is sensitive to the number concentration, particle size distribution (PSD), phase, density, fall rate, and spatial orientation of precipitation particles (Ryzhkov et al., 2011). These qualities are difficult to track accurately when a numerical model relies on the fixed PSDs frequently used within bulk microphysics schemes. The use of bin microphysics allows for explicit calculation of microphysical processes that affect cloud and precipitation formation and growth. In addition, the bin PSDs can be directly converted into radar reflectivity values that can be compared with observations. Where appropriate, we have separated results into convective and stratiform clouds to address the distinct microphysical and macrophysical changes occurring within those cloud regimes.

\section{Model description}

Numerical simulations were undertaken using the WRF version 3.1.1 developed by the National Center for Atmospheric Research (NCAR) as described in Skamarock et al. (2008). WRF solves the fully compressible, nonhydrostatic Eu- 
ler equations formulated on terrain following hydrostaticpressure coordinates and the Arakawa $\mathrm{C}$ grid. The model uses Runge-Kutta second- to sixth-order advection schemes in both horizontal and vertical directions. The fifth-order advection scheme is used in this study. The monotonic technique is employed for advection of scalar and moist variables. The cloud microphysical scheme is described below.

\subsection{Spectral bin microphysics (SBM)}

The original SBM (Khain et al., 2004) solves a system of kinetic equations for the size distribution functions for 7 hydrometeor types: water droplets, ice crystals (plate, column, and dendrite), aggregates, graupel, and frozen drops or hail. An eighth size distribution function exists for CCN. Each size distribution is represented by 33 mass doubling bins, where the mass of a particle in each bin is twice the mass of a particle in the preceding bin. A fast version of the SBM (FastSBM) with four size distributions of water drops, low density ice (ice crystals and aggregates), high density ice (graupel and hail), and aerosol (CCN) was created in order to substantially reduce the computational costs (Khain et al., 2009; Fan et al 2012a) and is the version used in this study. Further details about the mechanics of the SBM are found in Khain et al. (2004) and Fan et al. (2012a) and will not be repeated here.

In order to examine IN impacts on clouds and precipitation, an additional prognostic variable for IN particle (dust in this case) number concentration was added to the model as detailed in Fan et al. (2014). The prognostic IN variable, like the $\mathrm{CCN}$ distribution, does not account for removal of nuclei by precipitation, but does allow for regeneration of nuclei by hydrometeor evaporation. We update the heterogeneous ice nucleation parameterizations in the SBM (as detailed in Sect. 2.2) to connect ice formation with dust particle concentrations. While IN activation is affected by particle size, we assume all IN are equivalent in radii to the largest $\mathrm{CCN}$ bin to analyze the effects of the maximum potential ice activation for a given temperature and IN number concentration. In this study, a dust layer located between 1 and $3 \mathrm{~km}$ has been added to the dust case simulations, to reproduce a similar dust layer present in the observed case. The dust layer is initialized to cover the entirety of a certain domain at model start-up. The five outermost grid points are set to the initial IN number concentration at each model time step to prevent unnatural dilution of the IN supply. IN is thereafter transported exclusively from the lateral boundaries of the domain by wind advection for the duration of the simulation. The dust in the layer can serve as IN, CCN, or some fractional combination of the two by means of a simple partition that is set by the user depending on assumed or measured particle chemistry. This allows us to test the sensitivity of clouds within our model to a mixture of nuclei. We have set the dust layer to be IN exclusively in this study. Therefore, these dust cases will represent the maximum potential effects on hetero- geneous ice formation for a given dust number concentration. Additional information on the $\mathrm{CCN}$ and IN number concentration values used in this study is provided in Sect. 3 .

\subsection{Ice formation parameterizations}

The original SBM (Khain et al., 2004) included both homogeneous and heterogeneous ice formation, but did not directly connect ice formation to a prognostic IN variable. Liquid drop freezing for both homogeneous and immersion mechanisms was provided by Bigg (1953). Ice formation resulting from condensation and deposition freezing was provided by Meyers et al. (1992). Contact freezing was not included in the original SBM. In order to perform a study of aerosol impacts on heterogeneous ice formation, it is necessary to directly link ice nucleation rates to aerosol properties. The study of Gong et al. (2010), and more recently Fan et al. (2014), updated the available homogeneous freezing mechanisms and additionally implemented separate parameterizations into the SBM for depositional, contact, and immersion freezing, with ice formation in each of these schemes directly linked to the prognostic IN variable. In this study, we followed Bigg (1953) for homogeneous freezing of drops. The heterogeneous ice nucleation parameterizations employed are detailed below.

\subsubsection{Heterogeneous ice nucleation and freezing schemes}

Currently there is no deposition and condensational nucleation parameterization that is developed to connect with aerosol properties for DCC. As noted in Meyers et al. (1992) it is difficult to distinguish the relative contributions of depositional and condensational freezing in a parcel, since both form similarly sized small ice crystals, despite the different mechanisms of vapor to ice in the former and condensation followed immediately by freezing in the latter case. However, studies suggest that small ice crystals formed in the -5 to $-10^{\circ} \mathrm{C}$ temperature range can have a large impact on subsequent ice formation at higher altitudes (Ackerman et al., 2015; Hiron and Flossman, 2015; Lawson et al., 2015). A depositional-condensational scheme would allow for these small ice crystals to form in this specific temperature range. To link depositional and condensational freezing with aerosols, we follow the implementation of van den Heever et al. (2006), updated from the Meyers et al. (1992) parameterization. The number concentration of ice crystals generated by depositional-condensational nucleation $\left(N_{\text {dep }}\right)$ is proportional to the IN number concentration $\left(N_{\mathrm{IN}} ; \mathrm{L}^{-1}\right)$ within the grid cell by Eq. (1).

$N_{\mathrm{dep}}=N_{\mathrm{IN}} F_{\mathrm{M}}$,

where $F_{M}$ (unitless) is the function of the depositionalcondensational nucleation by Meyers et al. (1992) that represents the fraction of the maximum available IN $\left(N_{\mathrm{id}} ; \mathrm{L}^{-1}\right)$ 
concentration that may be activated for the given conditions as calculated in Eq. (2):

$N_{\mathrm{id}}=\exp \left\{-6.39+0.1296\left[100\left(S_{\mathrm{i}}-1\right)\right]\right\}$,

with $S_{\mathrm{i}}$ being the saturation over ice. The value of $F_{\mathrm{M}}$ is equal to 1 for conditions at ice supersaturation of $40 \%$, at which point all IN are activated, and is equal to 0 when supersaturation over ice is negative. For other values of ice supersaturation, $F_{\mathrm{M}}$ is equal to $N_{\mathrm{id}}$ divided by $N_{\mathrm{id}}\left(S_{\mathrm{i}}=40 \%\right)$. The initial size of an ice crystal formed by this scheme is assumed to be $2.5 \mu \mathrm{m}$ in radius and is assigned to the smallest ice size bin.

As stated above, the immersion freezing mechanism in the original SBM uses the parameterization of Bigg (1953), which is temperature-dependent only. To provide an aerosolbased immersion freezing scheme, we have incorporated the parameterization of DeMott et al. (2015), which was implemented by Fan et al. (2014) (cited as DeMott et al., 2013, in Fan et al., 2014, due to DeMott et al., 2015, not yet being published). The DeMott et al. (2015) immersion freezing number concentration is parameterized as in Eq. (3):

$$
\begin{aligned}
N_{\mathrm{imm}}= & (\mathrm{CF})\left(N_{\mathrm{IN}}\right)^{\left(\alpha\left(273.16-T_{\mathrm{k}}\right)+\beta\right)} \\
& \exp \left(\gamma\left(273.16-T_{\mathrm{k}}\right)+\delta\right) .
\end{aligned}
$$

$\mathrm{CF}$ is an instrumental correction factor with a value of 3 . Coefficients $\alpha, \beta, \gamma$, and $\delta$ are $5.95 \times 10^{-5}, 1.25,0.46$, and -11.6 , respectively, representing mineral dust particles (DeMott et al., 2015). $T_{k}$ is the cloud temperature in degrees Kelvin, $N_{\text {IN }}$ is the number concentration of total aerosol particles with diameter larger than $0.5 \mu \mathrm{m}$, and $N_{\mathrm{imm}}$ is the maximum number concentration of immersion ice possible in the given temperature range. Liquid drops are consumed over the size spectrum starting with the largest sizes down to the smallest until the minimum of $N_{\text {imm }}$ or drop number concentration is reached. According to Yin et al. (2005), drops with a radius smaller than $79.37 \mu \mathrm{m}$ will be frozen to pristine ice crystals, otherwise graupel is formed.

We have also adopted the contact freezing parameterization of Muhlbauer and Lohmann (2009), which is based on Cotton et al. (1986) and Young (1974). In this parameterization, contact freezing is a result of the collision of supercooled liquid water drops and IN due to Brownian motion. The contact freezing rate is therefore proportional to the drops' radius and number concentration. It is also proportional to the IN number concentration and Brownian diffusivity in air. Unlike Muhlbauer and Lohmann (2009) who calculated the freezing rate for the sum of all drops, we perform the calculation in this study for each spectral bin of drops. Then, the contact freezing number concentration $\left(N_{\mathrm{cnt}} ; \mathrm{L}^{-1} \mathrm{~s}^{-1}\right)$ for each individual size bin is represented by Eq. (4):

$N_{\mathrm{cnt}}=4 \pi r_{\mathrm{c}} N_{\mathrm{c}} D_{k} N_{\mathrm{IN}}$, where $r_{\mathrm{c}}(\mathrm{m})$ and $N_{\mathrm{c}}\left(\mathrm{m}^{-3}\right)$ is radius and number concentration of drops in the individual size bin, respectively. $D_{k}$ is the dust aerosol Brownian diffusivity $\left(\mathrm{m}^{2} \mathrm{~s}^{-1}\right)$, and is parameterized by Eq. (5):

$D_{k}=\frac{k_{\mathrm{B}} T C}{6 \pi \eta r}$,

where $D_{\mathrm{k}}$ is a function of the Boltzmann constant $K_{\mathrm{B}}=$ $1.28 \times 10^{-23} \mathrm{~m}^{2} \mathrm{~kg} \mathrm{~s}^{-2} \mathrm{~K}^{-1}, T$ is the air temperature, $r$ is the dry dust aerosol median radius, $\eta$ is the viscosity of air, and $C$ is the Cunningham slip correction factor. The viscosity of air depends on temperature, as calculated by Eq. (6):

$$
\begin{aligned}
\eta= & 10^{-5}\left[1.718+4.9 \times 10^{-3}(T-273.15)\right. \\
& \left.-1.2 \times 10^{-23}(T-273.15)^{2}\right] .
\end{aligned}
$$

The Cunningham slip correction factor is calculated by Eq. (7):

$C=1+1.26 \frac{\lambda}{r} \frac{1013.25}{p} \frac{T}{273.15}$,

where the molecular mean free path length of air $\lambda=$ $0.066 \mu \mathrm{m}, r$ is the dry aerosol radii, and $p$ is the pressure. To simplify the calculation, the contact freezing number concentration is the available dust number concentration $N_{\text {IN }}$, with freezing efficiency of 1 . Upon freezing, drops with a radius smaller than $79.37 \mu \mathrm{m}$ will be frozen to pristine ice crystals, larger drops will be frozen as graupel.

It should be noted that currently there is no ice nucleation parameterization specifically developed for DCC, and the understanding of ice nucleation for DCC is still very limited. The best we can do for model simulations at this time is to employ the currently available ice nucleation parameterizations for connecting with dust particles, evaluate our baseline simulation with observations, and carry out model sensitivity tests based on the validated case simulation to understand the dust impacts and associated mechanisms.

\subsection{Radar reflectivity calculations}

The liquid and frozen hydrometeor PSDs calculated by SBM can be easily converted into radar reflectivity values, providing a bridge for the comparison of model-simulated microphysical parameters with observable variables. For our study, we calculate radar reflectivity directly from the model's PSD for each of the individual hydrometeor species using the spherical particle approximations of the Rayleigh scattering equations suggested by Ryzhkov et al. (2011). Reflectivity is calculated for each bin and then summed over the entire PSD to obtain the total for each hydrometeor species (rain, snow, graupel), which are then combined to obtain the total reflectivity. The general equation for snow and graupel reflectivity 
is represented by Eq. (8):

$Z=\left(\frac{\rho_{\mathrm{s}, \mathrm{g}}}{\rho_{\mathrm{i}}}\right)^{2} \frac{\left|K_{\mathrm{i}}\right|^{2}}{\left|K_{w}\right|^{2}} \int_{0}^{\infty} D^{6} N(D) \mathrm{d} D$,

where $N(D)$ is the number concentration per cubic meter of snow (graupel) particles of diameter $D$ in millimeters. Density of snow or graupel is represented by $\rho_{\mathrm{s}, \mathrm{g}}$, while $\rho_{\mathrm{i}}$ is the density of solid ice. $\left|K_{\mathrm{i}}\right|^{2}$ and $\left|K_{\mathrm{w}}\right|^{2}$ represent the dielectric factors of solid ice and liquid water, respectively. When calculating the reflectivity for liquid drops, the two leading ratios are equal to 1 , but otherwise the equation is the same. The density relationship in the leading ratios can be expanded and simplified into a constant times the snow(graupel)-liquid density ratio, following Smith (1984) and Fovell and Ogura (1988) as in Eq. (9):

$$
\begin{gathered}
\left(\frac{\rho_{\mathrm{s}, \mathrm{g}}}{\rho_{\mathrm{i}}}\right)^{2} \frac{\left|K_{\mathrm{i}}\right|^{2}}{\left|K_{w}\right|^{2}}=\left(\frac{\rho_{\mathrm{s}, \mathrm{g}}}{\rho_{\mathrm{l}}}\right)^{2}\left(\frac{\rho_{\mathrm{l}}}{\rho_{\mathrm{i}}}\right)^{2} \frac{\left|K_{\mathrm{i}}\right|^{2}}{\left|K_{w}\right|^{2}} \\
=0.224\left(\frac{\rho_{\mathrm{s}, \mathrm{g}}}{\rho_{\mathrm{l}}}\right)^{2},
\end{gathered}
$$

where $\rho_{1}$ represents the density of liquid. This is then substituted into Eq. (1) to yield Eq. (10):

$Z=0.224\left(\frac{\rho_{\mathrm{s}, \mathrm{g}}}{\rho_{\mathrm{l}}}\right)^{2} \int_{0}^{\infty} D^{6} N(D) \mathrm{d} D$.

The reflectivity values calculated for liquid drops, snow, and graupel are then added together to obtain the total reflectivity, which is converted to $\mathrm{d} B Z$ by Eq. (11):

$$
Z_{\mathrm{d} B Z}=10 \log \left(Z_{\text {total }}\right)
$$

\section{Experiment design}

In our study, we have conducted experiments simulating the 8 March 2004 MCS described in Min et al. (2009), using realistic initial and boundary conditions. Four one-way nested domains were used (Fig. 1), with horizontal grid resolutions of $81,27,9$, and $3 \mathrm{~km}$ respectively and 41 vertical levels in each domain. Vertical level grid spacing is coarsest $(\sim 800 \mathrm{~m})$ at the top of the atmosphere, becoming progressively finer near the surface to a minimum of $\sim 30 \mathrm{~m}$. The numbers of horizontal grid points in each domain are $81 \times 81,81 \times 81,81 \times 81$, and $150 \times 150$, respectively. Initial and boundary conditions for the first domain are provided by the $1^{\circ} \times 1^{\circ} 6$-hourly National Centers for Environmental Prediction (NCEP) global final analysis dataset, with initial conditions for the other three domains being interpolated from the first domain. Due to the SBM not being designed to run at coarse resolutions, the SBM provides microphysics for only the $3 \mathrm{~km}$ resolution domain with bulk microphysics

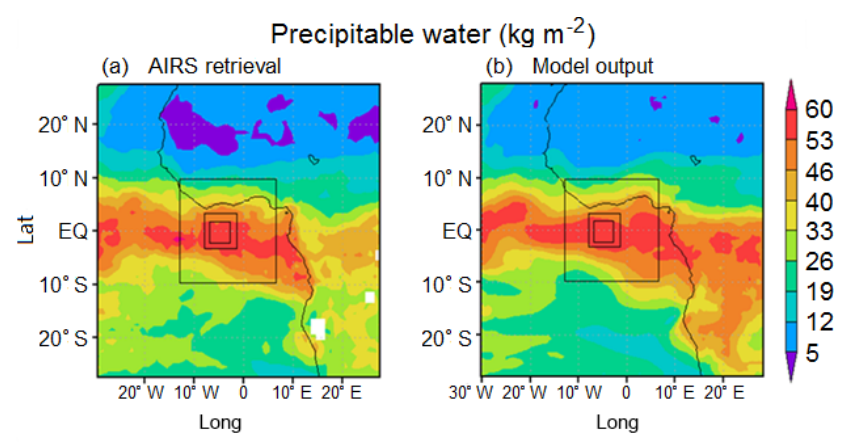

Figure 1. (a) AIRS total precipitable water averaged 79 March 2004, boxes denoting location of the three nested domains. (b) Domain 1 model output precipitable water averaged 79 March 2004.

being selected for domains $1-3$. The specific WRF parameterizations selected for the experiments are detailed in Table 1 . Each case was run for 33 model hours, beginning at 18 Z 7 March 2004.

The initial number concentrations of $\mathrm{CCN}$ are kept identical between the different cases. Typical marine aerosol number concentrations tend to be low, on the order of 300$600 \mathrm{~cm}^{-3}$ (O'Dowd et al., 1997; Yoon et al., 2007). Therefore, the $\mathrm{CCN}$ number concentration is set to a uniform value of $300 \mathrm{~cm}^{-3}$ below $2 \mathrm{~km}$ with the CCN number concentration being reduced exponentially from this value as height increases above $2 \mathrm{~km}$. The initial IN distribution is set to be vertically uniform at $.01 \mathrm{~cm}^{-3}$ for the Clean case. The dust cases add an increasing number concentration of IN to the Clean case's background value in a layer located vertically between 1 and $3 \mathrm{~km}$, as described by Min et al. (2009). The dust layer contributes IN to the smallest domain only, as the bulk microphysics used in the larger domains do not directly connect dust with ice formation. The dust cases are set with different IN number concentrations within the dust layer of $0.12 \mathrm{~cm}^{-3}$ (case D.12), $1.2 \mathrm{~cm}^{-3}$ (case D1.2), and $12 \mathrm{~cm}^{-3}$ (case D12), respectively. These values were selected based on aerosol measurements (Table 2) that were taken during the trans-Atlantic Aerosol and Ocean Science Expeditions (AEROSE) experiment (Morris et al., 2006) for dates coinciding with the observational study of the March 2004 dust outbreak detailed in Min et al. (2009). The dust loading was assumed to be the difference in the aerosol number concentrations of the dusty and pristine periods. Only aerosol particles with a radius greater than $0.5 \mu \mathrm{m}$ were considered when taking this difference, due to the smaller aerosol sizes being more prevalent during the pristine period compared to the dusty period. This size range is consistent with the study of DeMott et al. (2015) for ice-nucleating particles. The resulting dust number concentration was multiplied by an activation fraction suggested by Niemand et al. (2012) for Saharan dust to arrive at the number concentration used for case D.12. Other studies have suggested that dust-related IN num- 
Table 1. WRF model parameterizations selected for use in study simulations.

\begin{tabular}{ll}
\hline \multicolumn{2}{l}{ Selected Weather Research and Forecasting (WRF) model parameterizations } \\
\hline Parameterization & Selected option \\
\hline Microphysics & $\begin{array}{l}\text { Domain 1, 2, 3: Thompson (Thompson et al., 2008); } \\
\text { Domain 4: SBM (cited in text) }\end{array}$ \\
Cumulus & Domain 1, 2: Kain-Fritsch (Kain, 2004) \\
LW Radiation & Rapid Radiative Transfer Model (Mlawer et al., 1997) \\
SW Radiation & Dudhia scheme (Dudhia, 1989) \\
PBL & MYNN2 (Nakanishi and Niino, 2006) \\
Surface layer & MM5 similarity (Zhang and Anthes, 1982) \\
Land surface & RUC LSM (Smirnova et al., 1997)
\end{tabular}

ber concentrations greater than $1.0 \mathrm{~cm}^{-3}$ are possible (DeMott et al., 2003; Sassen et al., 2003; Ansmann et al., 2008), so two additional dust cases with IN number concentrations 1 (D1.2) and 2 (D12) orders of magnitude greater than the initial D.12 case were included in the study.

To prevent the $\mathrm{CCN}$ and IN fields from being diluted due to the inflow of air from the lateral boundaries, the $\mathrm{CCN}$ and IN number concentrations of the outer five grid cells (i.e., the boundary points) on each side of domain 4 are set to the initial values throughout the integration period. The initial vertical profile of domain averaged relative humidity shows moist $(>60 \% \mathrm{RH})$ air below $6 \mathrm{~km}$ and drier air $(<50 \% \mathrm{RH})$ above $6 \mathrm{~km}$, while the profiles of horizontal winds evidence weak $\left(<5 \mathrm{~m} \mathrm{~s}^{-1}\right)$ to relatively weak $\left(<10 \mathrm{~m} \mathrm{~s}^{-1}\right)$ wind speed below $7 \mathrm{~km}$, following the criteria used by Fan et al. (2009b). After the model's $6 \mathrm{~h}$ spin-up time, a relatively dry air layer corresponding to the SAL enters the domain via the NCEPFNL boundary conditions and is present for the duration of the simulation.

Additional criteria used to select subsets of the data for the purpose of our analysis are as follows. Cloudiness within an individual 3-D grid cell was determined by the sum of all condensates within it exceeding a $10^{-6} \mathrm{~kg} \mathrm{~kg}^{-1}$ threshold value, following the definition used in Fan et al. (2013). Cloud top was determined, from the top level of the model down to the surface, as the highest level with at least two consecutive levels exceeding the cloudiness threshold, which was intended to limit the influence of very thin clouds on the resulting analysis. While this does not take multiple cloud layers into account, it is similar to the top-down view of clouds observed by many satellites. To sort results by precipitation regime, we adapt the definitions of Fan et al. (2013) for convective and stratiform precipitation, with each vertical column classified as a single precipitation type only. For all precipitating clouds, surface rain rates must exceed $0.05 \mathrm{~mm} \mathrm{hr}^{-1}$. Convective precipitation is classified as precipitating column with vertical motion exceeding a $1 \mathrm{~m} \mathrm{~s}^{-1}$ threshold and cloud thickness of $8 \mathrm{~km}$ or greater. Nonconvective precipitating columns are classified as stratiform by the presence of ice-phase precipitation in the column. Nonprecipitating columns with a cloud layer thicker than $1 \mathrm{~km}$ and both cloud top and cloud bottom temperatures colder than $0{ }^{\circ} \mathrm{C}$ are classified as anvil clouds. Precipitating columns with cloud top temperatures warmer than freezing are classified as rain-producing warm clouds.

\section{Results}

Min et al. (2009) reported a unique case of a mature MCS partially under the effects of a Saharan dust outbreak. They noted distinct changes to cloud microphysical and macrophysical properties when comparing the dusty and dust-free sectors of the MCS. Large-scale meteorological conditions drive the initial cloud formation and growth processes, which are then modulated by aerosol indirect effects on cloud microphysical processes. Figure 1 describes the locations of the four model domains, displaying the Atmospheric Infrared Sounder (AIRS) retrieval (Fig. 1a) and the domain 1 modelsimulated precipitable water averaged over the duration of the simulation (Fig. 1b). The large-scale patterns of precipitable water are well reproduced by the model, although we note that the magnitude is slightly overestimated over the African continent and underestimated over the southern Atlantic compared to observations. Despite this, the magnitude in the location of our smallest domain is well reproduced, suggesting that the meteorological conditions in our region of interest are represented sufficiently well.

\subsection{Microphysical and macrophysical changes}

Increasing IN concentration in the dust cases results in greater ice formation and growth within the heterogeneous nucleation regime. This affects homogeneous ice formation by reducing the number concentration of liquid drops that reach the $-38^{\circ} \mathrm{C}$ threshold and also by reduced peak supersaturation values due to the growth of more numerous ice particles within the heterogeneous nucleation regime. Figures 2 and 3 depict the vertical cross section of a specific convective core and its associated stratiform-anvil cloud at a single model time step (hour 15) from the Clean and D1.2 cases. The cross section slices are not identically located in the two cases due to small differences in the spatial evolution of the system, but are less than three grid points apart. In both cases, the slices are similarly located within their respective cloud system and are at similar stages of evolution. The slices are averaged zonally over $9 \mathrm{~km}$ to further reduce the effects of spatial variations. The black and dashed blue lines (Figs. 2 and 3) depict updrafts $\left(>1 \mathrm{~m} \mathrm{~s}^{-1}\right)$ and downdrafts $\left(<-0.1 \mathrm{~m} \mathrm{~s}^{-1}\right)$. The grey dashed line (Figs. 2 and 3) depicts the threshold value of cloudiness suggested by Fan et al. (2013) and shows the change to cloud geometry directly. The Clean case (Fig. 2a) shows the classic DCC structure of convective core and associated stratiform region transitioning into the anvil. The D1.2 case also possesses a similar cloud structure, but with a far smaller anvil cloud, which is a 
Table 2. Ship-observed aerosol number concentrations from the AEROSE campaign corresponding to the March 2004 Saharan dust outbreak.

\begin{tabular}{lrrrrrr}
\hline \multicolumn{6}{l}{ March 2004 Ship-observed aerosol number } \\
\hline Radius $(\mu \mathrm{m})$ & $0.3-0.5$ & $0.5-1$ & $1-5$ & $5-10$ & $10-25$ & 25 \\
\hline Dust-free $\left(\mathrm{cm}^{-3}\right)$ & 108.6 & 10.5 & 2.36 & 0.1029 & $3.00 \mathrm{E}-4$ & $5.50 \mathrm{E}-8$ \\
Dust $\left(\mathrm{cm}^{-3}\right)$ & 87.32 & 34.7 & 7.557 & 0.3537 & $1.45 \mathrm{E}-3$ & $7.41 \mathrm{E}-6$ \\
\hline
\end{tabular}
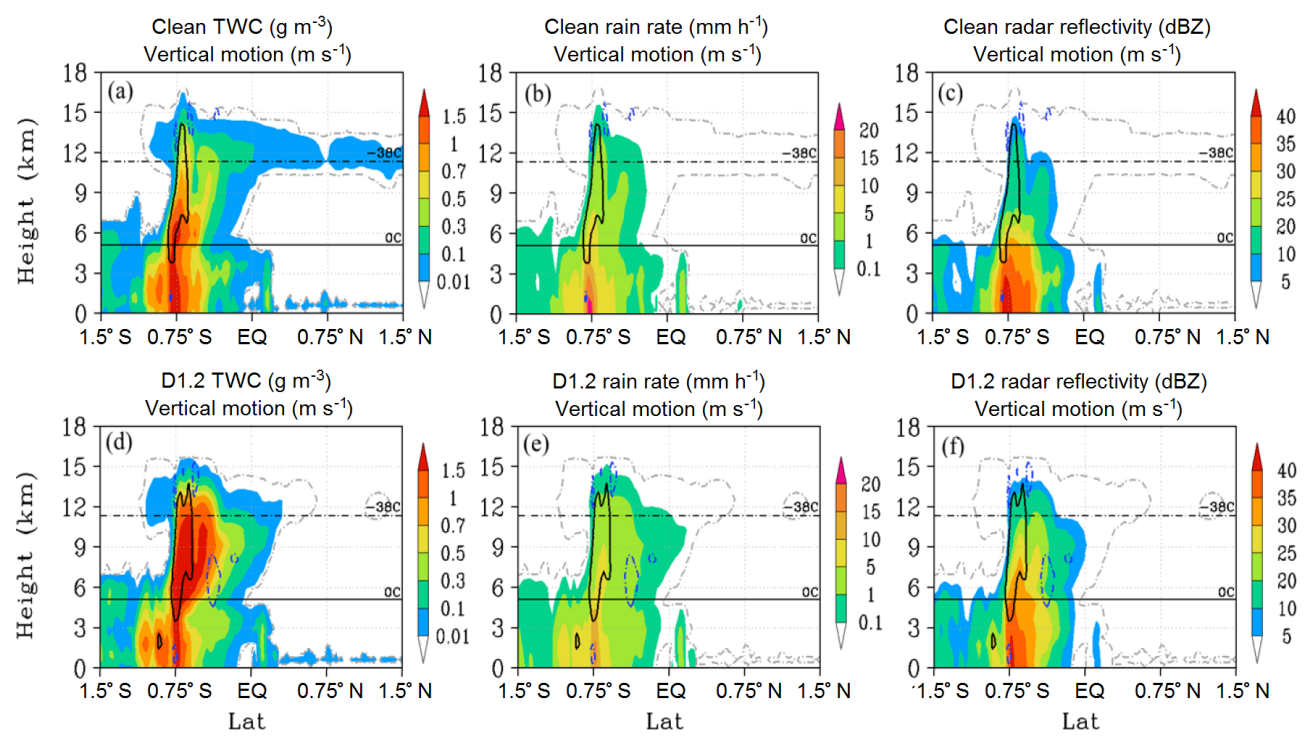

Figure 2. Zonally averaged longitude slice plot of similar DCC structures within the Clean (row 1) and D1.2 (row 2) cases. Shaded colors: total water content (TWC; column 1), vertical rain rate (column 2), and radar reflectivity (column 3); line contours, all columns: vertical motion (solid black $>1 \mathrm{~m} \mathrm{~s}^{-1}$; dashed blue $<-0.1 \mathrm{~m} \mathrm{~s}^{-1}$ ), cloudiness threshold (dashed grey, $>1 \times 10^{-6} \mathrm{~kg} \mathrm{~kg}^{-1}$ ).

result of the changes to the partition between homogeneous and heterogeneous ice formation in the D1.2 case. Cloud formation is increased in the heterogeneous nucleation regime (Fig. 2d) compared to the Clean case (Fig. 2a). Liquid drops that would otherwise freeze homogeneously at temperatures colder than $-38^{\circ} \mathrm{C}$ are converted to ice at warmer temperatures due to increased riming and/or immersion or contact nucleation. In addition, increased ice formation and growth within the heterogeneous nucleation regime reduces peak supersaturation values at colder temperatures, limiting ice formation in the homogeneous regime. Therefore, fewer cloud ice particles form within and/or are transported into the anvil regime, which limits its horizontal extent compared to the Clean case.

The first column of Fig. 2 describes total water content (TWC), while columns 2 and 3 describe rain rate and radar reflectivity, respectively. TWC is increased in the dust case (Fig. 2d) at temperatures below $0{ }^{\circ} \mathrm{C}$ compared to the Clean case (Fig. 2a). The higher TWC in the heterogeneous nucleation regime is accompanied by a correspondingly larger area of strong $\left(>1 \mathrm{~m} \mathrm{~s}^{-1}\right)$ vertical motion. This supports the evidence of convective invigoration due to increased latent heat release in the dust-affected deep, high-IWP clouds re- ported by Min and Li (2010). Stronger updrafts in the dust cases supply sufficient water vapor to support the formation and growth of more numerous particles in the heterogeneous nucleation regime and can transport a greater number of large particles to higher altitudes in the convective core and into the adjoining stratiform regime. These large particles contribute to the higher rain rate values noted in the D1.2 case (Fig. 2e) compared to the Clean case. The increased rain rates at temperatures below $0{ }^{\circ} \mathrm{C}$ also correspond to the increased radar reflectivity values in the stratiform regime from the convective core almost to the anvil regime near the equator (Fig. 2f). Figure 3 describes the effective radii $\left(\mathrm{Re} ; 1 \times 10^{2} \mu \mathrm{m}\right)$ of rain drops, graupel, and snow particles in columns $1-3$, respectively. Rain drop radii are significantly decreased in the heterogeneous nucleation regime (Fig. 3g) due to large-sized drops freezing by immersion or contact nucleation or by collisions with ice particles (riming), leaving smaller drops unfrozen. Graupel and snow radii are both decreased at temperatures below $0{ }^{\circ} \mathrm{C}$ (Fig. 3h, i). This reduction is most pronounced within the convective core where competition between more numerous small particles during collision-collection reduces growth rates. At temperatures above $0{ }^{\circ} \mathrm{C}$, graupel and snow radii are increased in the dust 

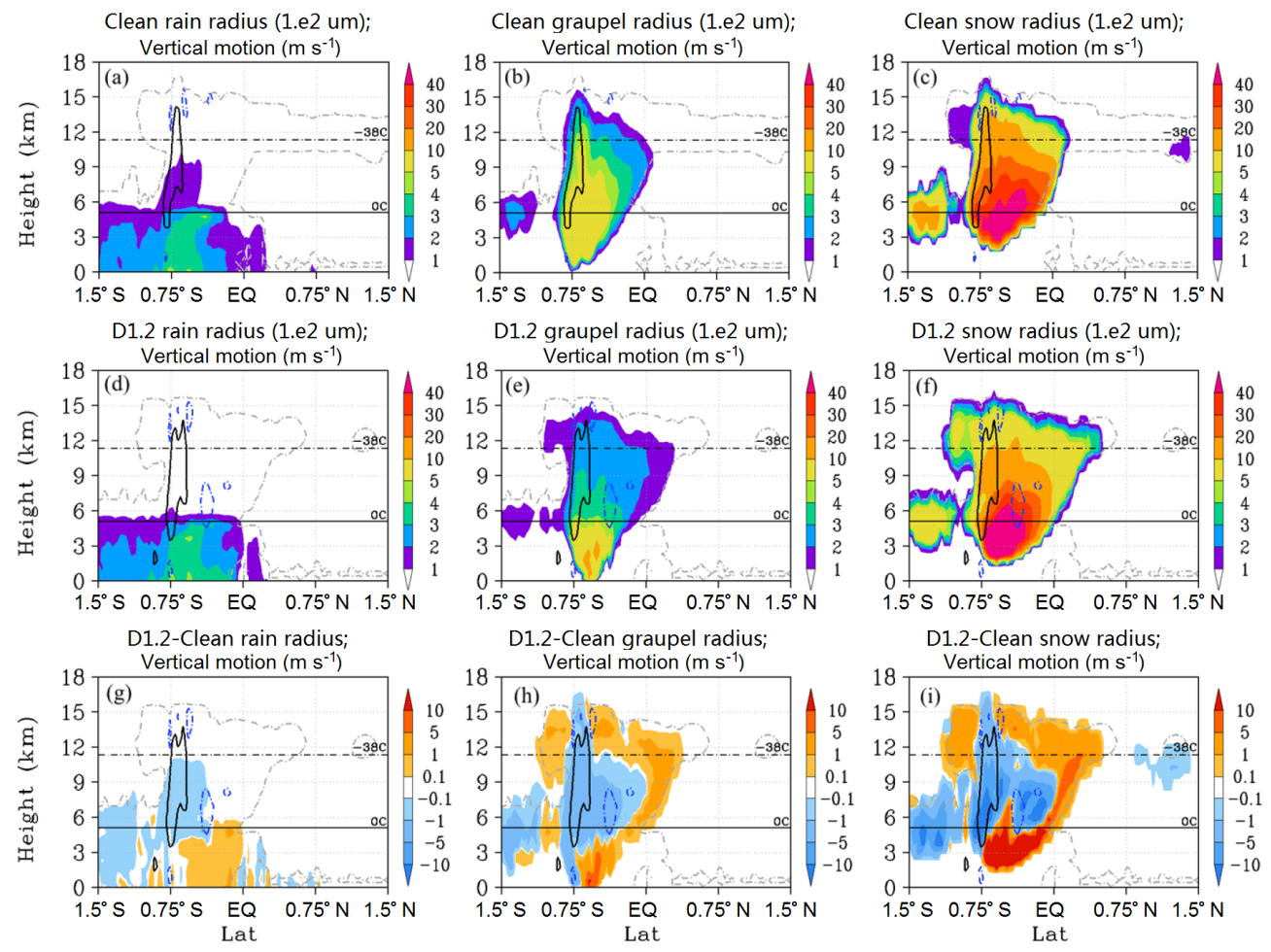

Figure 3. Slice plots representing same DCC as in Fig. 1 for Clean (row 1) and D1.2 (row 2) cases. Shaded colors: rain drop effective radii (Re; column 1), graupel Re (column 2), and snow Re (column 3); line contours, all columns: vertical motion (solid black $>1 \mathrm{~m} \mathrm{~s}{ }^{-1}$; dashed blue $<,-0.1 \mathrm{~m} \mathrm{~s}^{-1}$ ), cloudiness threshold (dashed grey, $>1 \times 10^{-6} \mathrm{~kg} \mathrm{~kg}^{-1}$ ).

cases due to immersion freezing of large rain drops within the heterogeneous nucleation regime and then falling into warmer temperatures. At temperatures below $-38^{\circ} \mathrm{C}$ and in the anvil cloud regime, graupel and snow radii are increased compared to the Clean case. This is due to the stronger outflow in the dust cases from the convective core, which transports large precipitation particles greater distances before they sediment out of the cloud. In addition, precipitation formation is shifted to colder temperatures (higher altitudes) in the heterogeneous nucleation regime, which increases the number of large particles forming near the cloud tops.

Aerosol indirect effects on cloud microphysical processes can result in a cloud top distribution that is higher or lower than would be expected for a given meteorological and/or environmental conditions. Figure 4 describes the changes to cloud top distribution in each of the three dust cases with respect to the Clean case. The cloud top distribution in Fig. 4 combines all cloud types together to describe the overall macrophysical changes due to increasing IN concentration. Figure $4 \mathrm{a}$ describes the time series of cloud top occurrence frequency for the Clean case. The percentage at each model time represents the horizontal sum of all cloud tops occurring at a given model level divided by the total horizontal and vertical sum of cloud tops occurring at that specific model output time. Figure $4 \mathrm{~b}$ through $\mathrm{d}$ describe the difference in cloud top percentage between the dust case and Clean case.
Increasing IN concentration from the D.12 case value in our simulations results in the overall cloud top height distribution shifting to lower altitudes (warmer temperatures). This is consistent with the findings of Min and Li (2010) in which higher AOD values were correlated with warmer cloud effective temperature. These macrophysical changes in cloud top distribution were noted to result in a strong cooling effect of thermal infrared radiation of up to $16 \mathrm{~W} \mathrm{~m}^{-2}$.

The cloud system transitions from shallow to deep convection between model hours 6 to 12. The majority of cloud tops occurring before hour 10 are warmer than $-5^{\circ} \mathrm{C}$. Therefore, the temperature and supersaturation conditions within these clouds are not sufficient for IN to activate and form ice crystals. Hence, the effects of increasing IN are limited during this time period. After the transition to deep convection, the cloud top distribution in the dust cases is shifted to lower altitudes (warmer temperatures) between model hours 12 and 24. Cloud tops occur less frequently above $15 \mathrm{~km}$ and more frequently between 12 and $13 \mathrm{~km}$ as a result of the changes in the partition between homogeneous and heterogeneous ice formation. This is most pronounced in the D1.2 and D12 cases, which both feature significant increases in heterogeneous ice formation compared to the Clean case. The numerous ice crystals that form when large concentrations of IN are activated compete for available water vapor during diffusional growth. The consumption of the cloud's available wa- 
ter vapor reduces peak supersaturation at colder temperatures and suppresses homogeneous ice nucleation. We note that the shift in cloud top distribution is not linear with increasing IN number concentration. While both the D1.2 and D12 cases feature lowered clouds (hour 12-24), the differences in the D12 case are not as pronounced as in the D1.2 case. This is a result of greater number concentrations of small cloud ice particles from heterogeneous ice formation in the D12 case compared to the D1.2 case. The small ice particles remain near the cloud top after larger particles sink down, yielding a higher cloud top distribution relative to the D1.2 case. From model hour 20 onwards, the cloud top distribution is significantly lowered in the D12 case compared to the D1.2 case. The small IN number concentration in the D.12 case results in a cloud top distribution that is different from both the D1.2 and D12 cases. From model hour 20 onwards, the D.12-Clean case difference plot suggests that higher cloud tops are occurring compared to the other cases. This would indicate that average hydrometeor particle sizes are smaller, allowing for increased vertical transport and slower sedimentation rates near the cloud tops. Similar increases in vertical transport can also occur due to aerosol effects on the liquid phase of DCC increasing particle mobility (Koren et al., 2015; Chen et al., 2017), although in our current study, CCN concentrations have not been changed. This suggests that IN concentration may also play a complimentary role in cloud top height enhancement in addition to changes CCN number concentration noted by previous studies. Future work related to the partition between IN and CCN activation in the dust layer will provide additional understanding of the interactions between these effects. The corresponding overall changes to cloud top height (averaged over model hours 6$33)$ are Clean $(12.64 \mathrm{~km}), \mathrm{D} .12(12.79 \mathrm{~km},+1.14 \%), \mathrm{D} 1.2$ $(12.33 \mathrm{~km},-2.49 \%)$, and D12 (12.13 km, $-4.08 \%)$.

\subsection{Effects on primary ice formation and hydrometeor number concentrations}

As noted previously, the convective core is the primary determiner of cloud macrophysical properties such as cloud top height and anvil cloud area (Futyan and Del Genio, 2007). However, changes to cloud microphysical processes resulting from AIE will modulate these macrophysical properties differently depending on the aerosol ice-liquid nucleation activity, aerosol number concentration, and environmental conditions in which clouds are forming (Khain and Pokrovsky, 2004; Khain et al., 2004, 2005, 2008; van den Heever et al., 2006; Fan et al., 2007b; Min et al., 2009, 2014; Min and Li, 2010; Li and Min, 2010; Altaratz et al., 2014). In our numerical simulations, increasing IN in the dust cases increases the total number concentration of new ice crystals forming in the heterogeneous nucleation regime between -5 and $-38^{\circ} \mathrm{C}$ (Fig. 6b-d). This affects the vertical distribution of cloud ice particles by changing the locations of initial ice formation and subsequent growth. Figure $5 \mathrm{a}$ and $\mathrm{b}$
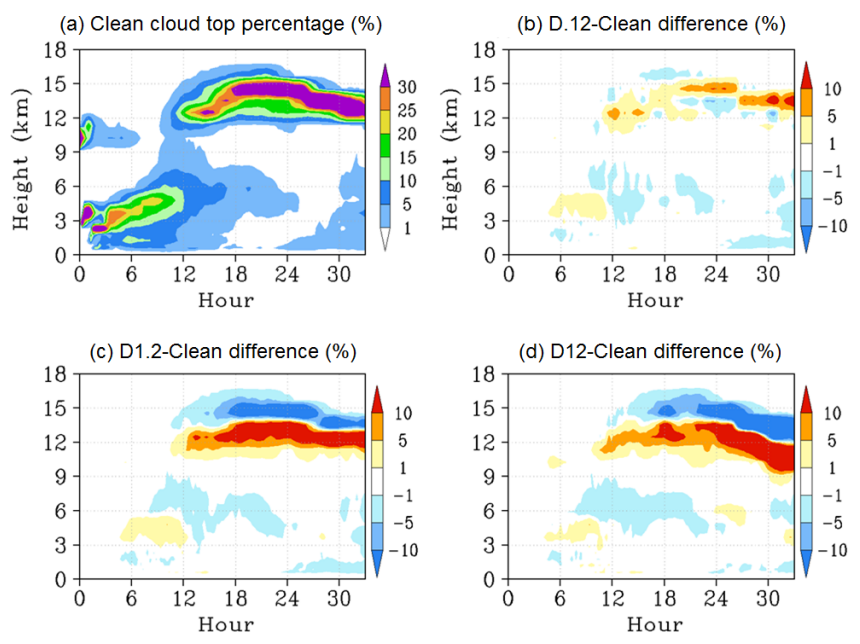

Figure 4. Time series of percentage of cloud tops occurring at each altitude for the (a) Clean case and the associated dust case minus Clean case difference plots for the (b) D.12-Clean, (c) D1.2-Clean, and (d) D12-Clean cases.

describe the vertical distribution of ice particles formed by the model's heterogeneous and homogeneous ice formation schemes in the convective and stratiform cloud regimes, respectively. The ice formation number concentration at each vertical level is summed horizontally and with respect to time for each cloudy pixel in the specified cloud regime and is represented by a $\log _{10}$ value. Figure $5 \mathrm{c}$ describes the vertical distribution of residual (nonactivated) IN number concentration in the convective cloud regime. This value is averaged over all convective cloud data points and temporally over the duration of the simulation. Increasing IN concentration in the convective core results in significant increases in ice formation between -5 and $-15^{\circ} \mathrm{C}$. Ice formation in this temperature range can deplete available IN (Fig. 5c) and reduce heterogeneous ice formation between -15 and $-38^{\circ} \mathrm{C}$. This depletion effect is substantial between $\sim 7$ and $11 \mathrm{~km}$ in the D.12 and D1.2 cases. When the IN concentration is sufficiently high, such as in the D12 case, depletion is not as significant as in the other cases and ice formation is significantly increased over the majority of the -5 to $-38^{\circ} \mathrm{C}$ temperature range. At the $-38^{\circ} \mathrm{C}$ threshold, ice formation number concentration is progressively reduced as IN number concentration is increased, which suggests that clouds are glaciating at warmer temperatures compared to the Clean case. Homogeneous freezing is reduced due to both fewer liquid drops crossing the $-38^{\circ} \mathrm{C}$ threshold (Fig. 6j-1) and reduced peak supersaturations resulting from increased ice growth at temperatures above $-38^{\circ} \mathrm{C}$. Finally, we note that stratiform ice formation is also increased in the dust cases compared to the Clean case. The increase, while not as large as in the convective core, contributes to increased cloudiness in the stratiform regime between -5 and $-38^{\circ} \mathrm{C}$ by increasing local concentrations of small, slow-falling ice crystals. 

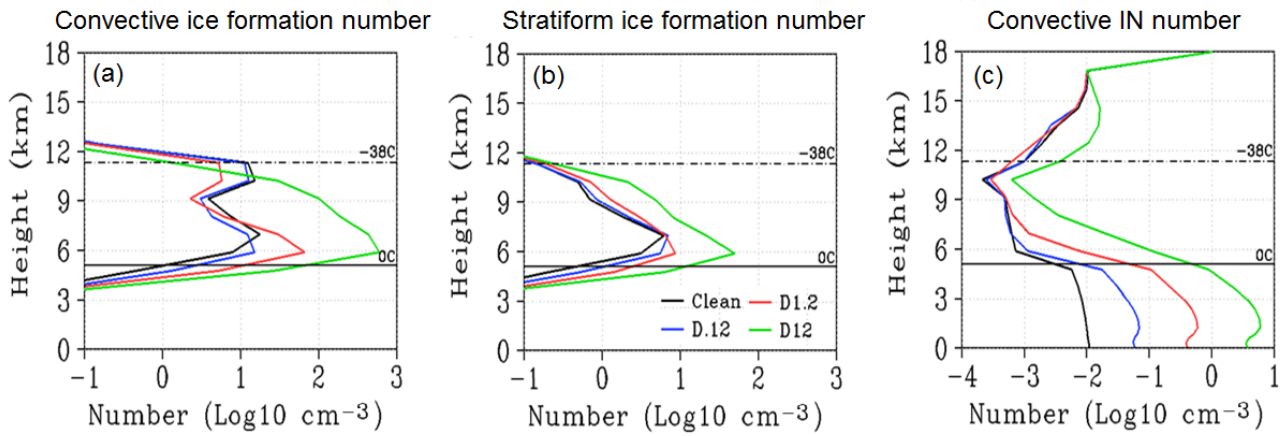

Figure 5. Vertical profile of combined heterogeneous and homogenous ice formation number $\left(\log _{10}, \mathrm{~cm}^{-3}\right)$ summed horizontally and over the duration of the simulation for convective (a) and stratiform (b) clouds, respectively. Convective-cloud-averaged and time-averaged vertical profile of residual (nonactivated, in-cloud) IN number concentration ( $\log _{10}, \mathrm{~cm}^{-3}$ ). Colors represent Clean (black), D.12 (blue), D1.2 (red), and D12 (green) cases, respectively.

Changes to the location and number concentration of initial ice particle formation affect the vertical distribution of ice and liquid hydrometeors in several ways. Figure $6 a-d$ describe the time evolution of convective averaged ice and snow particle number concentration. Increasing IN concentration results in a greater number concentration of ice or snow particles in the heterogeneous nucleation regime and a corresponding reduction within the cloud column at temperatures below $-38^{\circ} \mathrm{C}$. This indicates that the reduced homogeneous ice formation number concentration noted in Fig. 5a is not counteracted by the transport of a similar number of particles from temperatures warmer than $-38^{\circ} \mathrm{C}$. While more particles are formed in the heterogeneous nucleation regime between -5 and $-38^{\circ} \mathrm{C}$ compared to the Clean case, there are also more opportunities for these particles to collide and be incorporated into larger particles. For example, more frequent riming of ice and snow particles in the dust cases increases the formation of graupel (Fig. 6eh). More frequent riming in turn reduces the average number concentration of liquid drops in the convective regime at temperatures colder than $-5^{\circ} \mathrm{C}$ (Fig. 6i-1). While dust only activates as IN and not CCN in our simulations, average liquid drop number concentration at temperatures above $-5^{\circ} \mathrm{C}$ is affected by the more numerous ice particles forming in the heterogeneous nucleation regime and subsequently melting after falling into warmer temperatures. Small ice particles melt into small drops that may evaporate, while large drops formed from melted snow or graupel may collect smaller drops by collision-coalescence or break up into smaller drops themselves.

\subsection{Effects on convective PSDs and collection processes}

Increasing the total number concentration of ice particles formed in the heterogeneous nucleation regime affects the PSD in two ways. First, available water vapor is partitioned over a greater number of smaller particles. Second, these smaller particles are less efficient at colliding with other par- ticles. Both effects reduce the growth rates of the individual particles and shift the PSD to smaller particle sizes overall. The SBM allows us to examine the effects of dust on the PSD of the different hydrometeors without creating an arbitrary distinction between cloud- and precipitation-sized particles. Dust-related changes to the bin PSD of each hydrometeor type are described in Fig. 7. The provided radii values of the represented hydrometeor species are derived from the precalculated bin radii values used by the model, which are based on assumed particle densities and the mass doubling relationship between the individual bins. Contour values represent $\log _{10}$ values of bin number concentration. The difference plots likewise describe the relative change of these $\log _{10}$ values, representing $\log _{10}$ (Dust/Clean) values. As dust in our study acts as IN exclusively and not CCN, we focus our discussion on the -5 to $-38^{\circ} \mathrm{C}$ degree range conducive to heterogeneous nucleation and freezing. Since dust in nature can also act as effective $\mathrm{CCN}$ and may therefore be removed from the system by warm rain processes before freezing occurs, these results should be interpreted as an upper range of IN effects for a given dust number concentration.

Figure $7 \mathrm{a}, \mathrm{e}$, and i describe time series of the PSD averaged over convective data within the -5 to $-38^{\circ} \mathrm{C}$ temperature range for ice or snow, cloud or rain drops, and graupel. The remaining plots in Fig. 7 describe the differences between the three dust cases and the Clean case. The addition of IN to the DCC system produces an initial burst of ice formation covering the range of the PSD. In the D.12 and D1.2 cases, this is followed by a reduction in the small crystals and an increase in larger crystals and snow between hours 12 and 24. IN concentration has been depleted during this time period, which reduces the formation of small ice crystals. Existing ice crystals grow by particle collection into snow, hence the upwards slope in the difference contours between hour 12 and 24. The liquid PSD describes an enhancement to the largest drop sizes that could be the result of increased collision-coalescence of available drops and/or the recircula- 

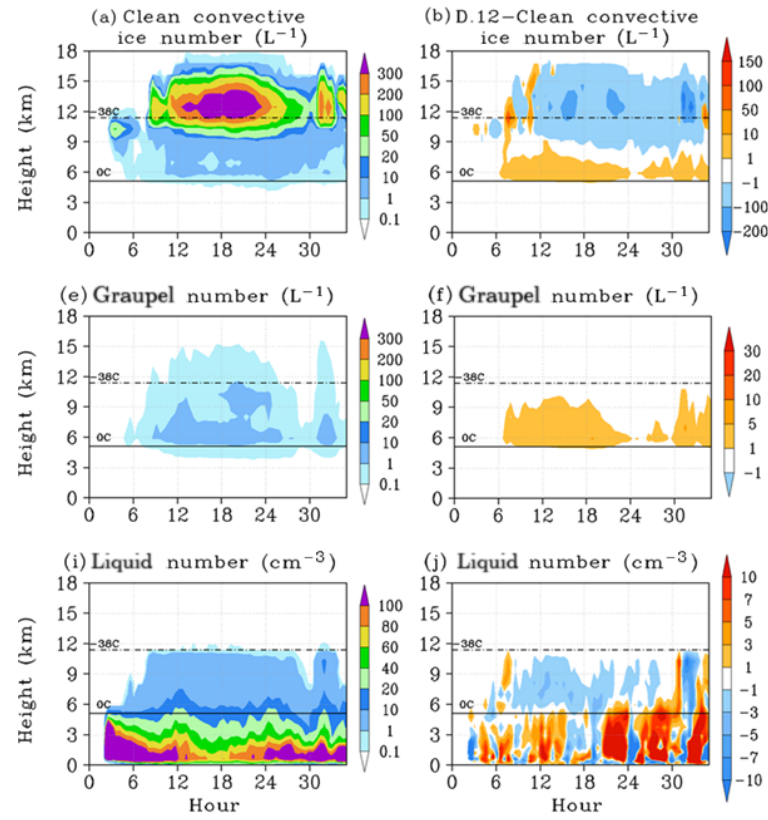
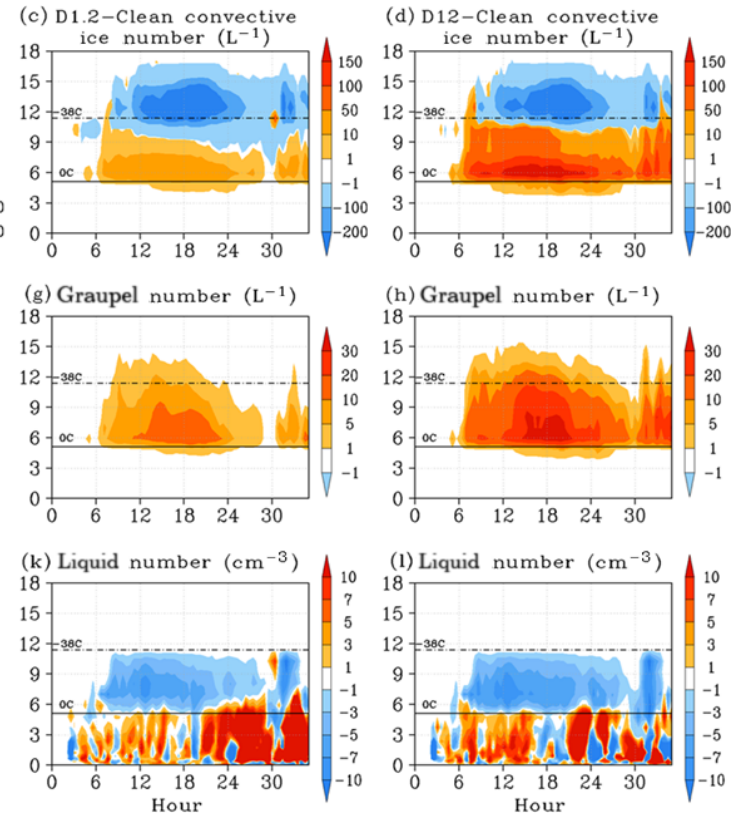

Figure 6. Convective-cloud-averaged profiles (height vs. time) and dust case minus Clean case difference plots of ice number concentration (a-d), graupel number concentration (e-h), and liquid number concentration (i-l). Columns: Clean (a, e, i), D.12 - Clean (b, f, j), D1.2 Clean $(\mathbf{c}, \mathbf{g}, \mathbf{k})$, and D12 - Clean $(\mathbf{d}, \mathbf{h}, \mathbf{l})$ cases.

tion of recently melted large ice particles to temperatures below freezing. Stronger vertical motion in the dust cases may also transport more large drops from temperatures above $0^{\circ} \mathrm{C}$ directly. The middle size range of the liquid PSD is reduced though the duration of the simulation, corresponding with the enhanced bin population in the graupel PSD. The formation of graupel in our model occurs by two distinct mechanisms: direct freezing of large liquid drops, by the homogeneous or immersion or contact freezing mechanisms, and collisions between liquid and ice particles (riming). There is evidence of increased large drop freezing, as seen by the enhancement to the largest bin sizes in the graupel PSD. However, the majority of graupel particles are formed by riming, as seen by the similar locations of reduction and enhancement between the liquid and graupel PSDs. While riming is more frequent in the dust cases, as evidenced by the increasing graupel number concentration, the graupel sizes shift smaller. This is a result of both overall smaller ice crystals sizes and competition between the individual particles for available liquid drops during riming, reducing growth rates (Fig. 8).

Particle collection processes are the primary source of precipitation formation due to the more rapid accumulation of mass compared to purely diffusional growth. In liquid clouds, collision-coalescence processes allow cloud drops to collect into rain drops. In ice and mixed phase clouds, ice-ice (aggregation) collisions and ice-liquid (riming) collisions become more frequent as total frozen particle number concentration increases. Figure 8 describes the changes to aggregation (row 1), riming (row 2), and drop autocon- version (row 3) in the convective regime with respect to time for the Clean and dust cases. Drop autoconversion rate $\left(1 \times 10^{4} \mathrm{~kg}^{-1} \mathrm{~s}^{-1}\right)$ tracks the formation of rain drops from cloud drops by collision-coalescence processes. As a single size distribution is used for liquid drops, rain drops are distinguished from cloud drops by the corresponding bin mass. Drop masses with equivalent radii greater than $20 \mu \mathrm{m}$ are classified as rain drops. Aggregate number $\left(\mathrm{kg}^{-1} \mathrm{~s}^{-1}\right)$ tracks the change of ice particles before and after aggregation occurs and is more negative for a more efficient process. Riming rate $\left(\mathrm{g} \mathrm{kg}^{-1} \mathrm{~s}^{-1}\right)$ tracks the liquid mass converted to graupel through the riming process and, again, is more negative for a more efficient process. These two processes are also affected by the relative availability of liquid and ice content within the cloud. As riming can only occur where ice and liquid particles coexist, this limits the most significant riming to the convective core below the cloud's glaciation level. Likewise the drop collision-coalescence processes are reduced in the heterogeneous nucleation regime in the dust cases due to the conversion of liquid content into ice at temperatures below $0{ }^{\circ} \mathrm{C}$. In the stratiform regime, relatively little liquid content is transported from the convective core due to the majority of freezing occurring in the core itself. Therefore, ice-ice particle interactions are the most common in the stratiform regime and snow is the predominant precipitation particle type (Stith et al., 2002; Heymsfield et al., 2002; Lawson et al., 2010, Gallagher et al., 2012).

In the Clean case the majority of ice forms by homogeneous freezing, which limits significant ice-ice particle in- 

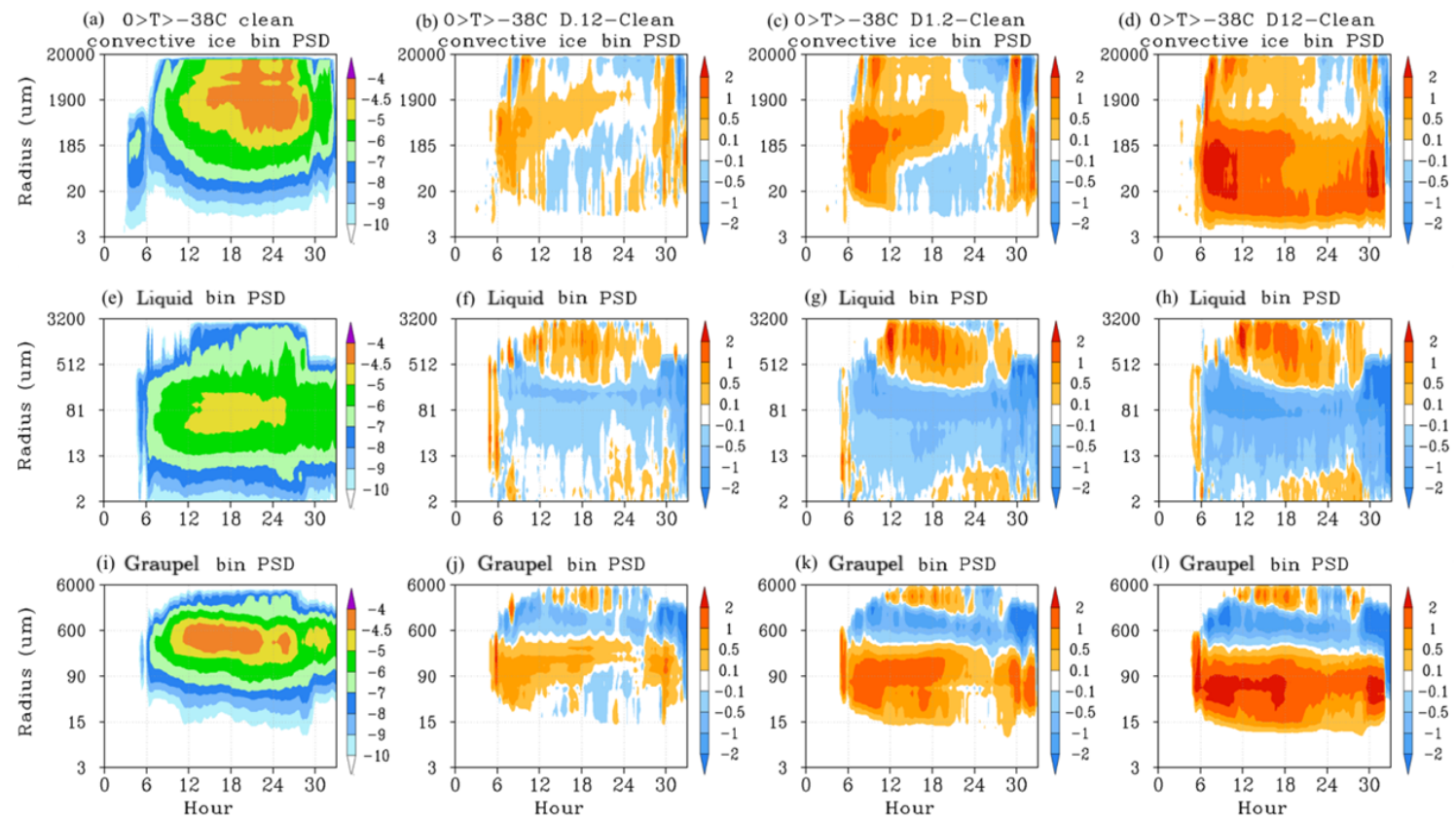

Figure 7. Time series and dust case minus Clean case difference plots of ice or snow bin particle size distribution (PSD; a-d), liquid bin PSD (e-h), and graupel bin PSD (i-l); averaged over the convective regime in the temperature range of -5 to $-38^{\circ} \mathrm{C}$. Contours represent $\log _{10}$ values of bin population. Columns: Clean (a, e, i), D.12 - Clean (b, f, j), D1.2 - Clean (c, g, k), and D12 - Clean (d, h, l) cases.

teractions in the heterogeneous nucleation regime until a significant number of ice particles have fallen down from the homogeneous freezing regime. The small addition of IN in the D.12 case forms a sufficient concentration of ice particles to increase aggregation activity before hour 18 near the $0{ }^{\circ} \mathrm{C}$ freezing level, but a noticeable gap at higher altitudes in the heterogeneous nucleation regime remains due to more significant homogeneous freezing compared to the other dust cases. Increasing the IN concentration further results in maximum values near $0{ }^{\circ} \mathrm{C}$ and decreasing upwards to colder temperatures. The significantly larger values of aggregation number in the D12 case compared to the other cases (Fig. 8a-d) is a result of the greater number concentration of ice crystals forming at warmer temperatures where particle "sticking" efficiency is higher (Hallgren and Hosler, 1960). While aggregation is the primary precipitation process in the stratiform regime, the aggregation numbers in this regime are smaller than in the convective regime. This is a result of the significantly greater number concentration of ice crystals that form initially in the core and are subsequently collected into snow particles before being transported into the stratiform regime.

The effect of increased heterogeneous ice formation on the efficiency of riming is tied into both the size and number concentration of ice particles that form and the overall availability of liquid water drops. The larger midlevel liquid water content in the Clean case results in efficient riming despite the lower ice concentration in the heterogeneous nucleation regime compared to the dust cases. Increased ice forma- tion in the heterogeneous nucleation regime increases riming rates near the $0^{\circ} \mathrm{C}$ freezing level. This is due to the greater total number concentration of ice particles and the significant presence of liquid water content near the melting level. Above $6 \mathrm{~km}$ in the convective regime, where ice formation becomes significant in the dust cases, riming rates become progressively lower as IN number concentration is increased. In general the addition of IN to the dust cases results in lower liquid water content in the heterogeneous nucleation regime due to riming and immersion or contact drop freezing, which limits the opportunities for collision-coalescence to occur. At altitudes below $6 \mathrm{~km}$, collision-coalescence rates are affected by the number concentration and PSD of ice particles that melt after falling into above-freezing temperatures. We note that higher autoconversion numbers occur at temperatures slightly above $0^{\circ} \mathrm{C}$ between hour 15 and 20 in the D1.2 (Fig. 8 row 3c) and D12 (Fig. 8 row 3d) cases.

\subsection{Changes to convective intensity and core top height}

The formation of smaller and more numerous cloud ice particles in the heterogeneous nucleation regime results in increased latent heat release in the convective core between -5 and $-38^{\circ} \mathrm{C}$. This is due to both the diffusional growth of frozen particles and latent heat released by the phase change occurring during riming. Diffusional growth is the source of the majority of latent heat release and may consume much of the updraft's available water vapor. Increased latent heat release invigorates convective updrafts compared 

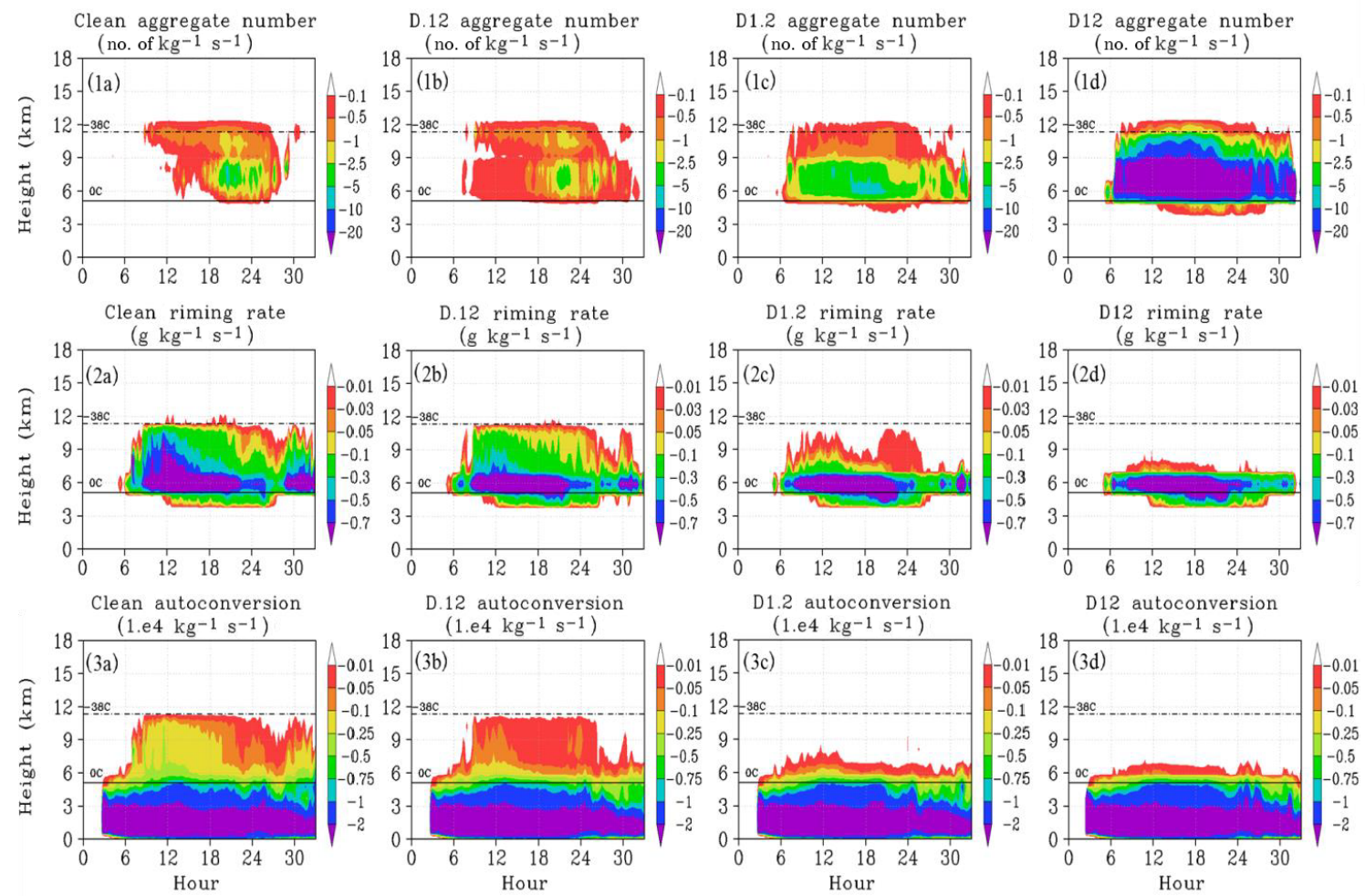

Figure 8. Time series of convective averaged aggregate number (row 1), riming rate (row 2), and drop autoconversion (collision-coalescence) number. Columns: Clean, D.12, D1.2, and D12 cases, respectively.

to the clean case. Figure 9a and d describe the time evolution of convective regime averaged updraft and downdraft velocity. Figure $9 \mathrm{~b}$ and e (Fig. 9c and f) describe the average latent heat (water vapor mixing ratio) at temperatures $<0{ }^{\circ} \mathrm{C}$ within the updrafts and downdrafts, respectively. As IN concentration is increased, average convective updraft intensity is progressively increased between hour 10 and 20 . Likewise, updraft latent heat is increased and updraft water vapor content is reduced. This is consistent with increased diffusional growth of the more numerous particles that form in the dust cases. Increased convective updraft velocity in the dust cases results in higher convective core top heights from model hour 6 to about model hour 20. During the transition to deep convection between hour 6 and hour 12 the core top height increase is fairly linear for increasing IN concentrations. The time-averaged convective core height (cloud tops $<0{ }^{\circ} \mathrm{C}$ ), percent change from the Clean case, and sample variance between hour 6 and 12 are as follows: Clean $(8.91 \mathrm{~km}$; $+0 \%$; 1.36), D. $12(8.93 \mathrm{~km} ;+0.25 \% ; 1.35)$, D1.2 (9.28 km; $+4.2 \% ; 0.89)$, and D12 (9.34 km; +4.8\%; 0.76). Despite the invigorated updrafts occurring throughout the hour 6 to hour 20 time period, the core cloud top height is also affected by changes to the ice or snow PSD between hour 12 and hour 20 (Fig. 7). The average convective core height (cloud tops $<0^{\circ} \mathrm{C}$ ), percent change from Clean case, and sample variance between hour 12 and 20 are as follows: Clean
(12.1 km; +0\%; 0.95); D.12 (12.25 km; +1.2\%; 0.87); D1.2 (12.04 km; $-0.5 \%$; 0.67); D12 (12.61 km; +4.2\%; 0.49). Note that the average core height in the D1.2 case is lower than the Clean case during this time period due to the presence of more large- and fewer small-sized particles (Fig. 7c) as a result of the IN depletion described in Fig. 5. This limits the number of particles that remain aloft in the D1.2 case, due to faster sedimentation rates of the large particles. Stronger downdrafts occurring between hour 10 and 20 also increase evaporation and sublimation of the more numerous particles in the dust cases. This consumes latent heat and increases water vapor content within the convective downdrafts (Fig. 9e, f).

To summarize, increasing the IN number concentration in the dust cases results in increased ice formation and growth within the heterogeneous nucleation regime between -5 and $-38^{\circ} \mathrm{C}$. Partitioning of available water vapor over more numerous particles shifts the PSD of cloud ice crystals to smaller sizes, which grow more slowly. The diffusional growth of these particles increases latent heat release in the heterogeneous nucleation regime and invigorates convective updrafts. Homogeneous ice formation is reduced due to the lower number concentration of liquid drops crossing the $-38^{\circ} \mathrm{C}$ threshold as well as reduced peak supersaturation due to ice growth within the heterogeneous regime. Despite reduced homogeneous ice formation, invigorated updrafts re- 

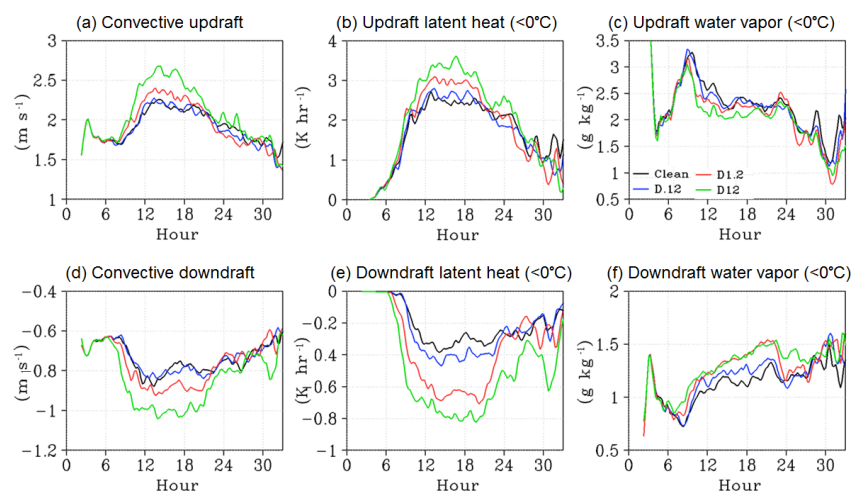

Figure 9. (a)-(c) Time series of average convective updraft intensity. Time series of average latent heat $\left(\mathrm{K} \mathrm{hr}^{-1}\right)$ within convective updrafts $\left(<0^{\circ} \mathrm{C}\right)$. Time series of average water vapor content $\left(\mathrm{g} \mathrm{kg}^{-1}\right)$ within convective updrafts $\left(<0^{\circ} \mathrm{C}\right)$. (d)-(f) As (a-c), averaged over convective downdrafts. Colors represent Clean (black), D.12 (blue), D1.2 (red), and D12 (green) cases, respectively.

sult in higher convective core cloud tops overall compared to the Clean case.

\subsection{Effects on stratiform cloud regime}

The macrophysical and microphysical properties of the stratiform and anvil cloud regime are significantly affected by cloud and precipitation formation processes initiated within the convective core and are also affected by changes to local ice formation within the stratiform-anvil regime itself. Invigorated updrafts in the dust cases carry a greater number of both large and small particles in the convective core to the level of divergence. These particles are then transported by the upper level winds into the milder updraft environment of the stratiform regime. The large particles quickly sediment out and the smaller particles remain aloft. Figure 10 describes the stratiform ice or snow bin distribution as Fig. 7 described the convective ice or snow bin distribution. Between hour 6 and hour 12 in the dust cases, the initial burst of ice formed by heterogeneous nucleation in the core is transported into the stratiform regime in conjunction with additional local ice formation. This results in increased bin populations over much of the ice or snow PSD. After hour 12 until about hour 26 , the formation of small ice particles is reduced due to the depletion of IN by ice formation earlier in the simulation. Snow particles formed in the convective core grow to larger sizes during transport into the stratiform regime. This increases the relative bin populations at sizes between 1900 and $20000 \mu \mathrm{m}$ compared to the convective regime. These large particles efficiently capture other smaller particles, resulting in the greater reduction of smaller sized particles in the stratiform PSD compared to the convective regime (Figs. 7c and 10c). When IN concentrations are not as significantly depleted, such as in the D12 case, heterogeneous nucleation produces additional small ice crystals throughout the hour
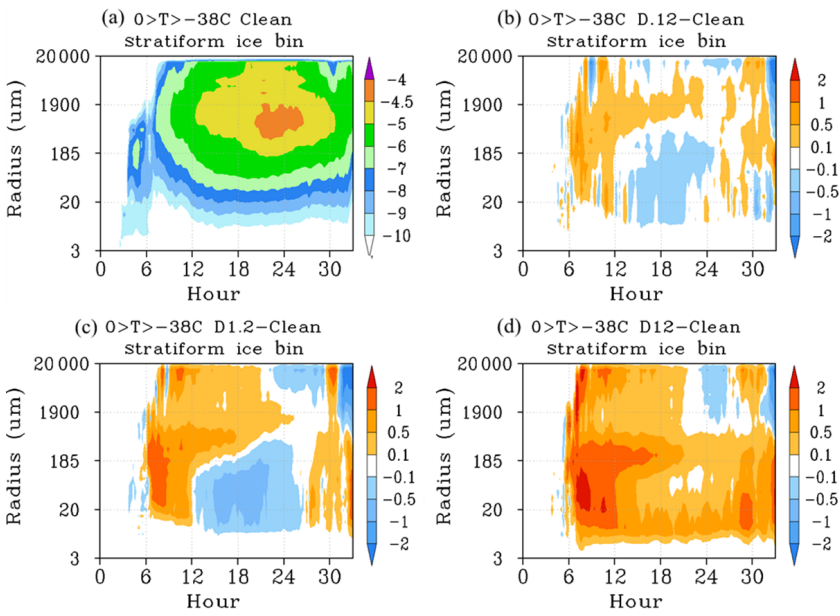

Figure 10. Time series and dust case minus Clean case difference plots of ice or snow bin particle size distribution (PSD), averaged over the stratiform regime in the temperature range of -5 to $-38^{\circ} \mathrm{C}$. Contours represent $\log _{10}$ values of bin population.

12 to hour 26 period (Fig. 10d). While larger sized particles continue to form in the D12 case, the location of the most significant enhancement to bin population shifts to smaller particle sizes compared to the D1.2 case due to competition between the more numerous particles during collection processes.

Many hydrometeors in the stratiform and anvil cloud regime were initially formed in the convective core and were transported into the stratiform-anvil regime by upper level winds. However, increasing IN concentration in the dust cases also results in increased heterogeneous ice formation within the stratiform-anvil regime itself (Fig. 5b), which affects cloudiness. Figure 11 describes the cloud occurrence numbers for the convective, stratiform and nonprecipitating anvil cloud regimes. The vertical distribution of convective cloud occurrence increases between -5 and $-38^{\circ} \mathrm{C}$ as IN concentration is increased in the dust cases. Likewise, stratiform cloud occurrence is increased between -5 and $-38^{\circ} \mathrm{C}$ due to both increased transport from the convective core and increased heterogeneous ice formation within the stratiform regime itself. However, the anvil cloud is significantly affected by changes in hydrometeor PSDs. A small IN concentration in the dust layer (D.12) results in greater anvil cloud occurrence compared to the Clean case. In the D.12 case, due to the limited supply of IN, the formation of large ice particles is not significantly increased compared to the small ice particles that form. The small ice particles are transported greater distances in the updrafts and sediment out slowly, which results in a higher (Fig. 4) and broader cloud distribution compared to the Clean case. In the D1.2 case, some ice particles are transported from the core and more ice particles are formed locally through heterogeneous formation processes with available IN in the stratiform regime. 

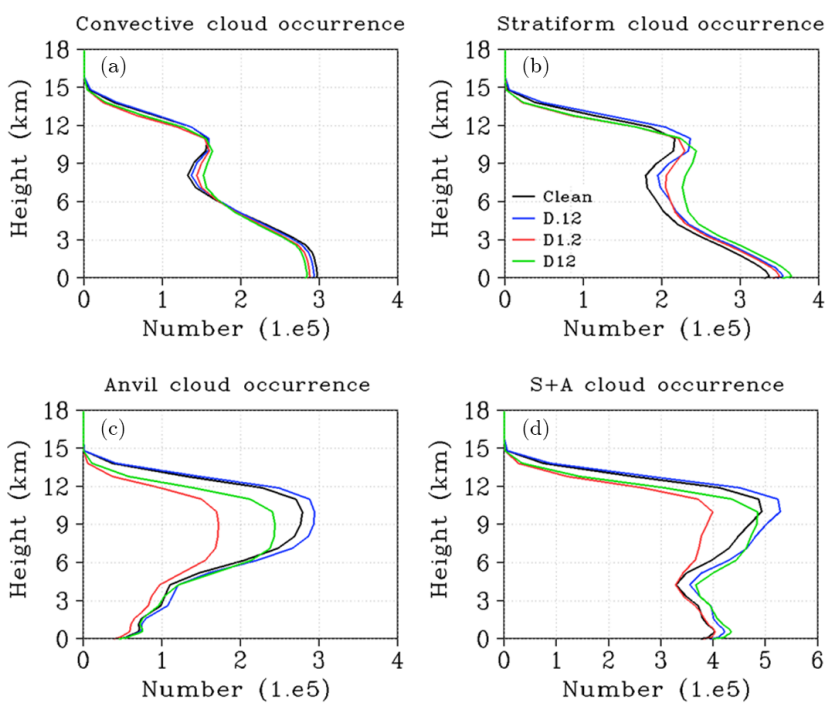

Figure 11. Occurrence frequency of cloudy data points over total simulation time for convective (a), stratiform (b), anvil (nonprecipitating) (c), and stratiform plus anvil ( $\mathrm{S}+\mathrm{A}, \mathbf{d})$ clouds. Colors represent Clean (black), D.12 (blue), D1.2 (red), and D12 (green) cases, respectively.

Some of the particles grow by collection processes to large sizes (Fig. 10c). These large particles sediment out quickly in the weaker updrafts of the stratiform regime and therefore are not transported into the anvil cloud regime. In conjunction with reduced homogeneous ice formation, this results in fewer particles forming locally within and/or being transported into the anvil regime. Therefore the stratiform-anvil cloud top distribution in the D1.2 case is lower and narrower compared to the Clean case and other dust cases. The D12 case is affected by both the formation of more numerous ice large particles (compared to the D.12 case) and more numerous small ice particles (compared to the D1.2 case). The strong updraft intensities in the D12 case transport significant condensate mass into the stratiform regime. The large particles that form in the D12 case sediment out quickly, but the small ice particles remain near the cloud tops. This results in a stratiform-anvil cloud top distribution that is lower and less broad compared to the Clean and D.12 cases, but is higher and wider than the D1.2 case. However, after hour 20 (Fig. 10d) the ice particles in the D12 case grow to large sizes and sediment out. This results in the lower stratiform-anvil cloud top height, from hour 20 until the end of the simulation, in the D12 case compared to the D1.2 case (Fig. 4).

\subsection{Vertical rain rates and surface accumulation}

Increasing heterogeneous ice formation by increasing IN concentrations results in larger ice mass near the $0{ }^{\circ} \mathrm{C}$ temperature level, but greater competition between individual particles for water vapor and available small drops or crystals for collection shifts the formation of precipitation-sized particles to higher altitudes. Smaller particles that sediment out or are transported below the melting level are more likely to evaporate below the cloud due to a slower fall speed. These changes result in a reduced surface accumulation and enhanced rain rates above the freezing level. Figure 12 describes the accumulated surface rain rates (Fig. 12a, b) and rain rate vertical profile differences (Fig. 12d, e) for convective (column 1) and stratiform (column 2) regimes. Figure $12 \mathrm{c}$ describes the time series of total accumulated surface precipitation, while Fig. 12f describes the total fraction of precipitation formed at each vertical level, for the Clean and dust cases. In general, the addition of IN reduces the average surface rain accumulation for the convective (Fig. 12d) rain regime and increases it for the stratiform (Fig. 12e) rain regime. This is due to the different effects of dust on the primary sources of precipitation in the two regimes. The percent reduction of total surface precipitation in the dust cases from the Clean case values at the end of the simulation are as follows: D.12 (-1.14\%), D1.2 (-3.95\%), D12 (-6.02\%).

Convective rain is significantly affected by changes to graupel formation, which in the dust cases is shifted towards smaller sizes (Fig. 7). The smaller graupel sizes are a result of decreased riming rates above $6 \mathrm{~km}$ due to smaller ice particle sizes and lower liquid water content (Fig. 6). By the end of the simulation, convective surface precipitation accumulation is reduced from the Clean case as follows: D.12 $(-2.3 \%)$; D1.2 $(-5.5 \%)$; D12 $(-7.9 \%)$. In the stratiform regime precipitation is predominantly a result of snow formation. In the dust cases, snow formation is enhanced due to the increased transport of ice mass from the convective core and the warmer glaciation temperatures in the convective regime. This initiates the aggregation processes earlier in the simulation and at warmer temperatures than in the Clean case (Fig. 8). Stratiform surface precipitation accumulation is increased from the Clean case value as follows: D.12 (+10.1\%); D1.2 (+8.2\%); D12 (+13.1\%). At altitudes below $6 \mathrm{~km}$, collision-coalescence rates are affected by the number concentration and PSD of the frozen particles that melt in the above-freezing temperatures. In the convective regime, increased aggregation rates (Fig. 8) and freezing of large drops to graupel (Fig. 7) result in higher autoconversion rates in the D12 case compared to the other dust cases between $\sim 1 \mathrm{~km}$ and the $0{ }^{\circ} \mathrm{C}$ freezing level when these large particles melt. This partially counteracts the reduced rain rates between 4 and $8 \mathrm{~km}$, resulting in near-surface rain rates that slightly exceed the D1.2 case, although final surface accumulation is still lower in the D12 case due to the greater reductions at higher altitudes.

\subsection{Radar reflectivity CFADs}

With advances in observing technology, cloud and precipitation radars are used extensively for studying cloud and precipitation formation and microphysical-dynamical interactions. Min et al. (2009) used contoured frequency by alti- 

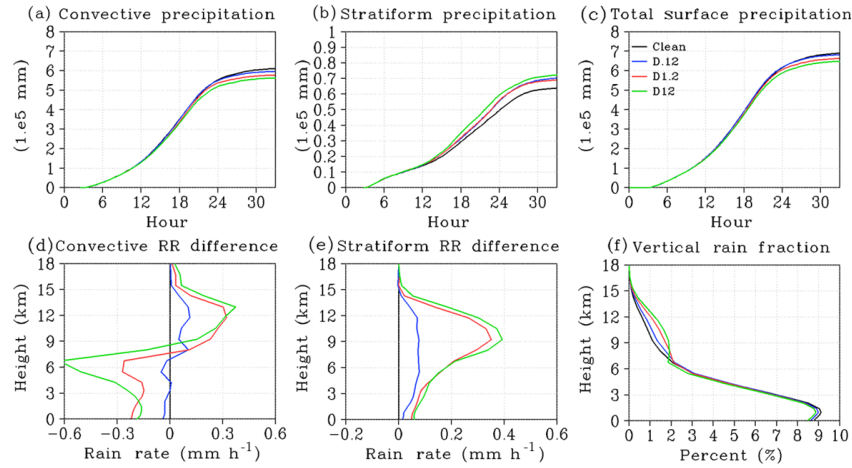

Figure 12. (a) and (b) Time series of accumulated surface precipitation for convective and stratiform data respectively. (c) Total accumulated surface precipitation for the clean and dust cases. (d) and (e) Dust case minus Clean case time-averaged vertical rain rates for convective and stratiform precipitation, respectively. (f) Fraction of total precipitation formed at each vertical level. Colors represent Clean (black), D.12 (blue), D1.2 (red), and D12 (green) cases, respectively.

tude (CFAD) plots to describe the observed changes to convective and stratiform radar reflectivity between the dusty and dust-free regions. They noted that radar reflectivity at temperatures above $0{ }^{\circ} \mathrm{C}$ was reduced in the dusty region in both the convective and stratiform regimes. At temperatures below $0{ }^{\circ} \mathrm{C}$, convective reflectivity was reduced in the dusty regions while stratiform reflectivity was increased. Min et al. (2009) performed an additional sensitivity test to differentiate the effects of dynamics on hydrometeor growth and precipitation formation from the microphysical effects of dust. The sensitivity test revealed that, in the absence of dust, relatively stronger convective intensity also resulted in higher stratiform reflectivity values. This indicated that the reduced reflectivity in the convective regime and increased stratiform reflectivity observed in the dust sector were a result of changes to microphysical processes rather than dynamics. These microphysical changes were suggested to be a result of increased heterogeneous ice formation, which delayed the formation of large precipitation particles in the convective regime until sufficient growth occurred during transport into the stratiform regime to pass the minimum reflectivity threshold (Min et al., 2009).

To compare the observations of Min et al. (2009) with our results, we have recreated similar CFAD plots using model derived reflectivity. Figure 13 describes the radar reflectivity CFADs of the convective and stratiform regimes for the Clean and three dust cases. As IN concentration is increased in the simulations, changes in ice formation and growth processes result in decreased convective reflectivity at temperatures above $0^{\circ} \mathrm{C}$. Likewise, stratiform reflectivity at temperatures below $0^{\circ} \mathrm{C}$ is increased in the dust cases. These changes suggest that increased heterogeneous ice formation is significantly affecting the formation of precipitation-sized parti- cles, consistent with the hypothesis of Min et al. (2009). We note that convective reflectivity at temperatures below $0^{\circ} \mathrm{C}$ and stratiform reflectivity at temperatures above $0^{\circ} \mathrm{C}$ are both increased in the dust cases compared to the Clean case. This differs from the reduced reflectivity values reported in Min et al. (2009) and Li and Min (2010) for these locations. These differences can be partially explained by greater water vapor content within the dust layer in the model simulations compared to the observed SAL.

Measurements from AIRS/AMSU/HSB indicate that the relative humidity in the dust layer is about $20 \%$ drier than the surrounding air. While a dry air layer is present in the WRF's initial and boundary conditions, the model slightly overestimates precipitable water compared to observations (Fig. 1). To examine the impacts of dust layer moisture content on our case study, we have conducted additional numerical simulations based on the D1.2 case. The dust layers within these test cases feature relative humidity values that are $5 \%$ drier than the original D1.2 case. The first case (Dry5init) reduces the water vapor content in the dust layer over the entire fourth domain at model start-up time. The boundary conditions entering the fourth domain are unchanged from the original D1.2 case. The second case (Dry5bound, not shown) reduces water vapor content at the boundaries of the fourth domain for the duration of the simulation with no changes made to the dust layer's initialized moisture content at model startup time. Figure 14 describes the convective and stratiform CFADs of the D1.2 and Dry5init cases. The first and second columns describe the D1.2 CFAD and the D1.2 minus Clean case difference plots, respectively. The third column describes the Dry5init minus Clean case difference plots. Reduced moisture content in the Dry5init case weakens convective cloud formation, which decreases convective reflectivity overall at temperatures below $0^{\circ} \mathrm{C}$ and shifts reflectivity to lower values at temperatures above $0^{\circ} \mathrm{C}$. Reflectivity in the stratiform regime is still increased compared to the Clean case at temperatures below $0^{\circ} \mathrm{C}$, but is also shifted to lower values at temperatures above freezing. These changes are very similar to the observed changes of convective and stratiform reflectivity described by Min et al. (2009) and Li and Min (2010). The Dry5bound case results in similar changes as those described by the Dry5init case, although with greater reductions in the convective regime and smaller increases in the stratiform regime as a result of the drier boundary air transported into the fourth domain for the duration of the simulation.

\section{Conclusions}

The MCS occurring on 8 March 2004 in the tropical eastern Atlantic, first described in Min et al. (2009), was simulated using the WRF model with a spectral-bin microphysical (SBM) scheme. Ice nucleation parameters within the SBM were updated to connect heterogeneous and homogeneous 

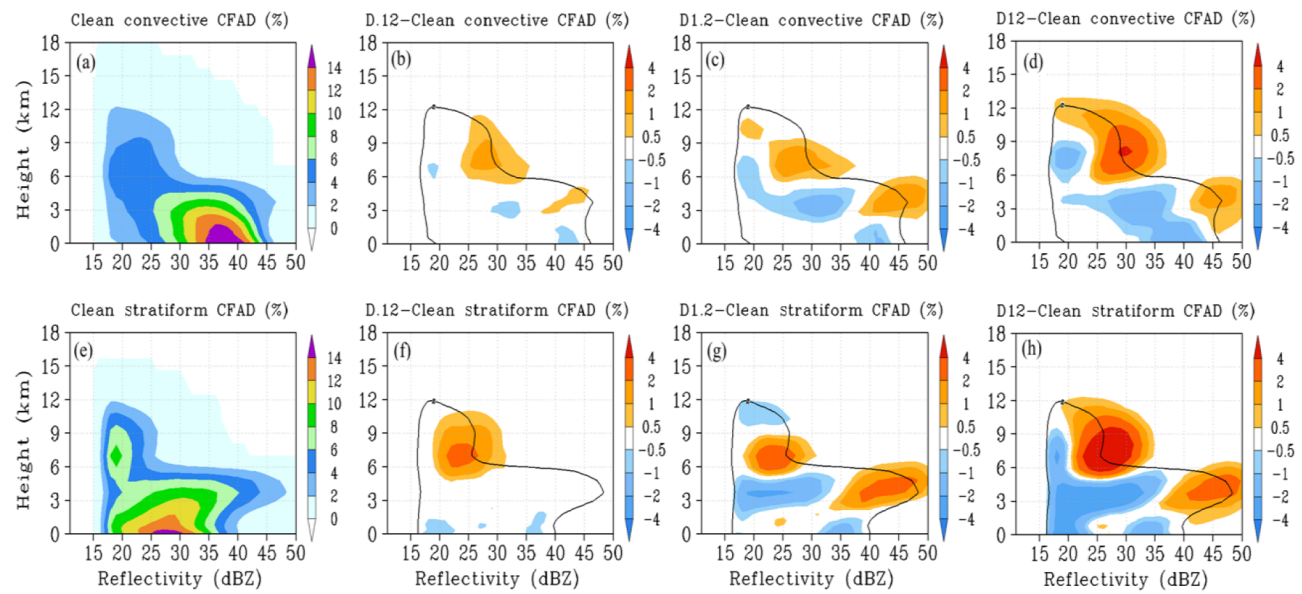

Figure 13. Contoured frequency by altitude diagrams (CFADs) of model-simulated convective (a-d) and stratiform (e-h) reflectivity. Columns: Clean case, D.12-Clean, D1.2-Clean, D12-Clean differences, respectively. Black contour line in difference plots represents the Clean case $2 \%$ contour value.
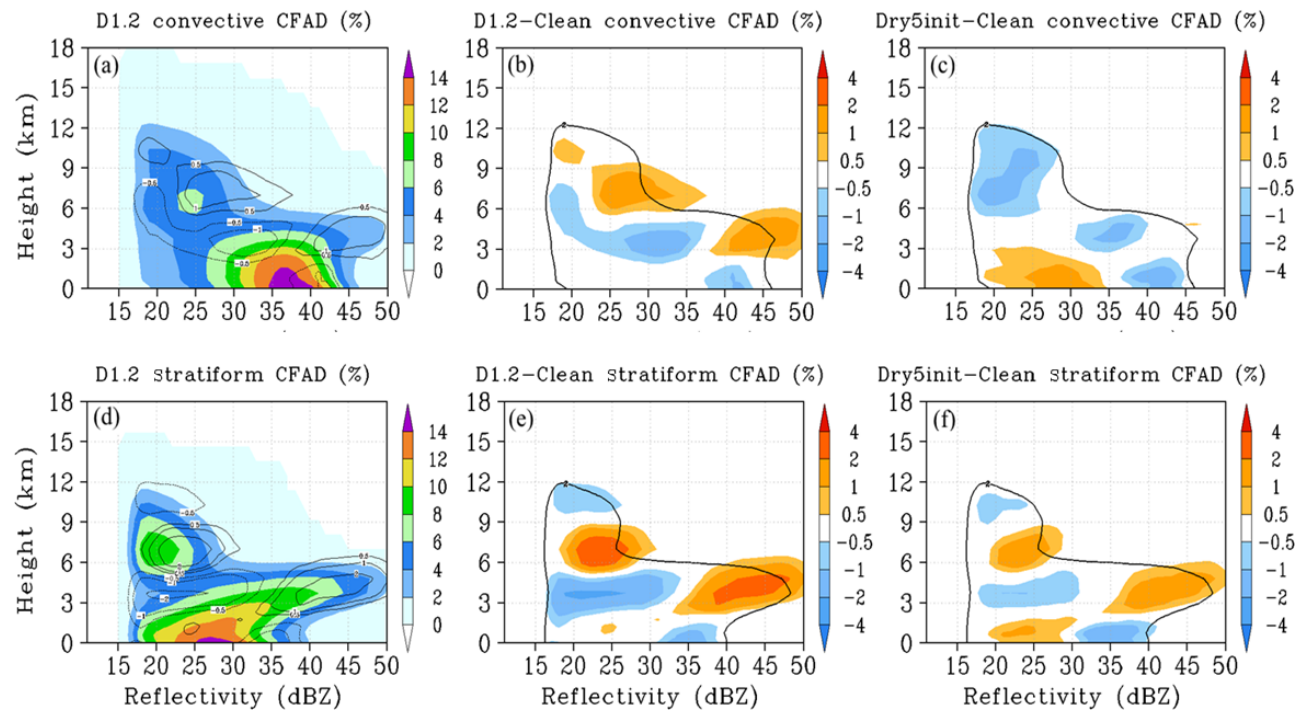

Figure 14. Contoured frequency by altitude diagrams (CFADs) of model-simulated convective (top row) and stratiform (bottom row) radar reflectivity. Columns: D1.2 case CFAD; D1.2-Clean case; Dry5init-Clean case. Dry5init case is based on the D1.2 case, but the dust layer is set to be $5 \%$ dryer at model start up. Boundary conditions are unchanged from the D1.2 case. Black contour line in difference plots represents the Clean case $2 \%$ contour value.

ice formation with IN to investigate the effects of dust acting as IN. We present the effects of IN activation on ice formation processes and the eventual effects on the large-scale cloud fields. The hypothesis of Min et al. (2009) suggested that dust particles forming ice at heterogeneous temperature ranges $\left(-5\right.$ to $\left.-38^{\circ} \mathrm{C}\right)$ results in changes to precipitation formation processes and ice particle size distributions shifting to smaller sizes in the heterogeneous nucleation regime. Lower stratiform-anvil cloud top heights were reported (Min and Li, 2010), despite the presence of more numerous deep clouds with large IWP, which suggests that convective invigoration (increased latent heat release; stronger updrafts) is occurring.
Increasing IN number concentration in the dust case simulations results in the formation of a greater number of ice particles in the convective core between -5 and $-38^{\circ} \mathrm{C}$ compared to the Clean case (Fig. 6). The partitioning of available water vapor over the greater number of particles results in smaller ice crystal and graupel sizes in the dust cases (Fig. 7). The ice particles grow more slowly due to the increased competition between individual particles for available water vapor (Fig. 9). In the dust cases, stronger diffusional growth and liquid-to-ice phase changes during riming of the smaller, more numerous particles lead to an increase in total ice mass, resulting in an increase in latent heat release in the hetero- 
geneous nucleation regime. Convective updrafts are invigorated (Figs. 2 and 9), resulting in increased overshooting and higher convective core top heights. The increased downdraft velocity in the convective regime is primarily a consequence of invigorated convective updraft intensity, which subsequently results in increased evaporation and sublimation of the more numerous small particles and latent cooling (Fig. 9).

Particle growth resulting from collection processes is also reduced, due to the lower collision efficiency of the smaller particle sizes in the dust cases. When available IN number concentration in the dust cases is depleted, the formation of new ice crystals in the heterogeneous nucleation regime is limited. Collection processes remove small ice crystals formed earlier in the simulation and increase the formation of large ice or snow particles in both the convective (Fig. 7) and stratiform (Fig. 10) regimes. This is most visible in the D1.2 case between hour 12 and hour 18. When few small ice particles remain aloft, due to reduced homogeneous ice formation and/or increased particle collection, stratiform-anvil cloud top heights will be lower over the majority of the simulation, as in the D1.2 and D12 cases (Figs. 4 and 11). When small particles are relatively more numerous and the number of large particles is not significantly affected, such as in the D.12 case, stratiform-anvil cloud top heights are higher than in the Clean case (Figs. 4 and 11). The small particles in the D.12 case are transported to higher altitudes in the convective updrafts and remain aloft for longer times. More numerous but smaller graupel particles form in the dust cases (Figs. 3 and 7) due to the reduced riming efficiency of small ice particles (Fig. 8) and increased competition between the individual frozen particles during riming for available liquid drops. The greater heterogeneous ice numbers also increase ice particle aggregation in the -5 to $-38^{\circ} \mathrm{C}$ temperature range (Fig. 8), leading to increased snow formation in both the convective and stratiform regimes (Figs. 7 and 10). Growth competition between the more numerous individual particles during riming and aggregation shifts precipitation formation to higher altitudes within the heterogeneous nucleation regime. This results in changes to simulated reflectivity values (Figs. 2 and 13), which are similar to observed effects on reflectivity (Min et al., 2009; Li and Min, 2010).

The impacts of dust as IN on model-simulated reflectivity are mostly consistent with observed changes, i.e., dust cases producing smaller reflectivity values near the surface and larger values above the freezing level and most significantly in the stratiform regime (Figs. 2 and 13). Radar reflectivity in the dust cases is affected by PSDs shifted to smaller sizes, reduced particle fall rates, and increased formation of large snow particles. The contribution of graupel and rain drops to total reflectivity in the dust cases is reduced due to the shift to smaller particle sizes (Figs. 3 and 7) and reduced drop concentrations (Fig. 6), respectively. This decreases dust case reflectivity values at temperatures above $0{ }^{\circ} \mathrm{C}$ in the convective regime (Fig. 2, Fig. 13). Snow particles have large radii com- pared to graupel and rain drops of comparable mass (Figs. 3 and 7) and have slower fall rates. More numerous large snow particles in the dust cases result in increased reflectivity values at temperatures below $0{ }^{\circ} \mathrm{C}$ (Fig. 13), most notably in the stratiform regime where aggregation is the dominant precipitation formation process. The dust case reflectivity CFADs differed from observed reflectivity changes in the convective regime $\left(>0{ }^{\circ} \mathrm{C}\right)$ and in the stratiform regime $\left(>0{ }^{\circ} \mathrm{C}\right)$. Specifically, reflectivity in these locations is increased in the dust case simulations while observations indicate that reflectivity is reduced. Higher moisture content in the dust layer compared to the observed test cases was suggested as a possible cause of these differences. Additional test cases based on the D1.2 case were simulated to determine the effects of reduced moisture content within the dust layer on model results. Reducing dust layer moisture content by $5 \%$ (Dry5init case) was sufficient to weaken convective cloud formation and affect the resulting reflectivity CFADs (Fig. 14) in ways consistent with observed changes (Min et al., 2009; Li and Min, 2010). Convective reflectivity $\left(<0^{\circ} \mathrm{C}\right)$ and stratiform reflectivity $\left(>0{ }^{\circ} \mathrm{C}\right)$ were both reduced compared to the Clean case. Stratiform reflectivity at temperatures below $0^{\circ} \mathrm{C}$ was also increased from the Clean case, indicating that microphysical changes to cloud and precipitation formation processes are similar to those in the original D1.2 case. Additional indepth study of the five interactions between dust-related microphysical effects and changes to latent heat processes has been planned for the near future to more fully address the interconnected nature of thermodynamical and microphysical effects occurring within DCC.

Data availability. The WRF model can be downloaded at http: //www2.mmm.ucar.edu/wrf/users/download/get_source.html (last access: 8 August 2018; Skamarock et al. 2008). The NCEP FNL reanalysis is available at https://doi.org/10.5065/D6M043C6 (National Centers for Environmental Prediction/National Weather Service/NOAA/U.S. Department of Commerce, 2000), and the AIRS V006 data can be downloaded from Goddard Earth Sciences Data and Information Services Center (GES DISC) at https://disc.gsfc.nasa.gov/datacollection/AIRS2RET_NRT_006. html (AIRS Science Team/Joao Texeira, 2016). The model and datasets mentioned above are publicly accessible after registration.

For WRF simulation output and more detail on the SBM scheme, please contact the corresponding author.

Author contributions. The first author, MG, conducted all the WRF simulations, analyzed the results and wrote the paper. The second author, QM, as MG's advisor, provided overall guidance on this study and paper writing. The third author, JF, provided advice on the SBM model.

Competing interests. The authors declare that they have no conflict of interest. 
Acknowledgements. This work was supported by the NSF under contracts AGS-1608735 and PIRE-1545917, and by the NOAA Educational Partnership Program with Minority Serving Institutions (EPP/MSI) under cooperative agreements NA17AE1625 and NA17AE1623. Jiwen Fan is supported by the US Department of Energy (DOE) Atmospheric System Research (ASR) Program. The Pacific Northwest National Laboratory (PNNL) is operated for the DOE by Battelle Memorial Institute under contract DE-AC0676RLO1830.

Edited by: Corinna Hoose

Reviewed by: two anonymous referees

\section{References}

Ackerman, A. S., Fridlind, A. M., Grandin, A., Dezitter, F., Weber, M., Strapp, J. W., and Korolev, A. V.: High ice water content at low radar reflectivity near deep convection - Part 2: Evaluation of microphysical pathways in updraft parcel simulations, Atmos. Chem. Phys., 15, 11729-11751, https://doi.org/10.5194/acp-1511729-2015, 2015.

AIRS Science Team/Joao Texeira: AIRS/Aqua L2 Near Real Time (NRT) Standard Physical Retrieval (AIRS-only) V006, Greenbelt, MD, USA, Goddard Earth Sciences Data and Information Services Center (GES DISC), https://disc.gsfc.nasa.gov/ datacollection/AIRS2RET_NRT_006.html (last access: 2 August 2018), 2016.

Altaratz, O., Koren, I., Reisin, T., Kostinski, A., Feingold, G., Levin, Z., and Yin, Y.: Aerosols' influence on the interplay between condensation, evaporation and rain in warm cumulus cloud, Atmos. Chem. Phys., 8, 15-24, https://doi.org/10.5194/acp-8-15-2008, 2008.

Altaratz, O., Koren, I., Remer, L. A., and Hirsch, E.: Review: Cloud invigoration by aerosols - Coupling between microphysics and dynamics, Atmos. Res., 140, 38-60, 2014.

Andreae, M. O., Rosenfeld, D., Artaxo, P., Costa, A. A., Frank, G. P., Longo, K. M., and Silva-Dias, M. A. F.: Smoking rain clouds over the Amazon, Science, 303, 1337-1342, 2004.

Ansmann, A., Tesche, M., Althausen, D., Müller, D., Seifert, P., Freudenthaler, V., and Dubovik, O.: Influence of Saharan dust on cloud glaciation in southern Morocco during the Saharan Mineral Dust Experiment, J. Geophys. Res.-Atmos., 113, D04210, https://doi.org/10.1029/2007JD008785, 2008.

Arakawa, A.: The cumulus parameterization problem: Past, present, and future, J. Climate, 17, 2493-2525, 2004.

Berg, W., L'Ecuyer, T., and van den Heever, S.: Evidence for the impact of aerosols on the onset and microphysical properties of rainfall from a combination of satellite observations and cloud-resolving model simulations, J. Geophys. Res.-Atmos., 113, D14S23, https://doi.org/10.1029/2007JD009649, 2008.

Bigg, E. K.: The formation of atmospheric ice crystals by the freezing of droplets, Q. J. Roy. Meteor. Soc., 79, 510-519, 1953.

Boose, Y., Welti, A., Atkinson, J., Ramelli, F., Danielczok, A., Bingemer, H. G., Plötze, M., Sierau, B., Kanji, Z. A., and Lohmann, U.: Heterogeneous ice nucleation on dust particles sourced from nine deserts worldwide - Part 1: Immersion freezing, Atmos. Chem. Phys., 16, 15075-15095, https://doi.org/10.5194/acp-16-15075-2016, 2016.
Boucher, O., Randall, D., Artaxo, P., Bretherton, C., Feingold, G., Forster, P., and Zhang, X. Y.: Clouds and aerosols, in: Climate change 2013: The physical science basis, Contribution of working group I to the fifth assessment report of the intergovernmental panel on climate change, 571-657, Cambridge University Press, Cambridge, 2013.

Braun, S. A.: Reevaluating the role of the Saharan air layer in Atlantic tropical cyclogenesis and evolution, Mon. Weather Rev., 138, 2007-2037, 2010.

Braun, S. A., Sippel, J. A., Shie, C. L., and Boller, R. A.: The evolution and role of the Saharan Air Layer during Hurricane Helene (2006), Mon. Weather Rev., 141, 4269-4295, 2013.

Carlson, T. N. and Prospero, J. M.: The large-scale movement of Saharan air outbreaks over the northern equatorial Atlantic, J. Appl. Meteorol., 11, 283-297, 1972.

Carrio, G. G. and Cotton, W. R.: Investigations of aerosol impacts on hurricanes: virtual seeding flights, Atmos. Chem. Phys., 11, 2557-2567, https://doi.org/10.5194/acp-11-2557-2011, 2011.

Chen, Q., Koren, I., Altaratz, O., Heiblum, R. H., Dagan, G., and Pinto, L.: How do changes in warm-phase microphysics affect deep convective clouds?, Atmos. Chem. Phys., 17, 9585-9598, https://doi.org/10.5194/acp-17-9585-2017, 2017.

Cotton, W. R., Tripoli, G. J., Rauber, R. M., and Mulvihill, E. A.: Numerical simulation of the effects of varying ice crystal nucleation rates and aggregation processes on orographic snowfall, J. Clim. Appl. Meteorol., 25, 1658-1680, 1986.

Cotton, W. R., Krall, G. M., and Carrió, G. G.: Potential indirect effects of aerosol on tropical cyclone intensity: Convective fluxes and cold-pool activity, Trop. Cyclone Res. Rev, 1, 293306, 2012.

DeMott, P. J., Sassen, K., Poellot, M. R., Baumgardner, D., Rogers, D. C., Brooks, S. D., and Kreidenweis, S. M.: African dust aerosols as atmospheric ice nuclei, Geophys. Res. Lett., 30, 1732, https://doi.org/10.1029/2003GL017410, 2003.

DeMott, P. J., Prenni, A. J., Liu, X., Kreidenweis, S. M., Petters, M. D., Twohy, C. H., and Rogers, D. C.: Predicting global atmospheric ice nuclei distributions and their impacts on climate, $\mathrm{P}$. Natl. Acad. Sci. USA, 107, 11217-11222, 2010.

DeMott, P. J., Prenni, A. J., McMeeking, G. R., Sullivan, R. C., Petters, M. D., Tobo, Y., Niemand, M., Möhler, O., Snider, J. R., Wang, Z., and Kreidenweis, S. M.: Integrating laboratory and field data to quantify the immersion freezing ice nucleation activity of mineral dust particles, Atmos. Chem. Phys., 15, 393-409, https://doi.org/10.5194/acp-15-393-2015, 2015.

Dudhia, J.: Numerical study of convection observed during the winter monsoon experiment using a mesoscale two-dimensional model, J. Atmos. Sci., 46, 3077-3107, 1989.

Dunion, J. P. and Velden, C. S.: The impact of the Saharan air layer on Atlantic tropical cyclone activity, B. Am. Meteorol. Soc., 85, 353-365, 2004.

Ekman, A. M. L., Engström, A., and Wang, C.: The effect of aerosol composition and concentration on the development and anvil properties of a continental deep convective cloud, Q. J. Roy. Meteor. Soc., 133, 1439-1452, 2007.

Evan, A. T., Dunion, J., Foley, J. A., Heidinger, A. K., and Velden, C. S.: New evidence for a relationship between Atlantic tropical cyclone activity and African dust outbreaks, Geophys. Res. Lett., 33, L19813, https://doi.org/10.1029/2006GL026408, 2006. 
Fan, J., Zhang, R., Li, G., and Tao, W. K.: Effects of aerosols and relative humidity on cumulus clouds, J. Geophys. Res.-Atmos., 112, D14204, https://doi.org/10.1029/2006JD008136, 2007.

Fan, J., Ovtchinnikov, M., Comstock, J. M., McFarlane, S. A., and Khain, A.: Ice formation in Arctic mixed-phase clouds: Insights from a 3-D cloud-resolving model with size-resolved aerosol and cloud microphysics, J. Geophys. Res.-Atmos., 114, D04205, https://doi.org/10.1029/2008JD010782, 2009a.

Fan, J., Yuan, T., Comstock, J. M., Ghan, S., Khain, A., Leung, L. R., and Ovchinnikov, M.: Dominant role by vertical wind shear in regulating aerosol effects on deep convective clouds, J. Geophys. Res.-Atmos., 114, D22206, https://doi.org/10.1029/2009JD012352, 2009b.

Fan, J., Comstock, J. M., and Ovchinnikov, M.: The cloud condensation nuclei and ice nuclei effects on tropical anvil characteristics and water vapor of the tropical tropopause layer, Environ. Res. Lett., 5, 044005, https://doi.org/10.1088/17489326/5/4/044005, 2010a.

Fan, J., Leung, L. R., Li, Z., Morrison, H., Chen, H., Zhou, Y., and Wang, Y.: Aerosol impacts on clouds and precipitation in eastern China: Results from bin and bulk microphysics, J. Geophys. Res.-Atmos, 117, D00K36, https://doi.org/10.1029/2011JD016537, 2012a.

Fan, J., Rosenfeld, D., Ding, Y., Leung, L. R., and Li, Z.: Potential aerosol indirect effects on atmospheric circulation and radiative forcing through deep convection, Geophys. Res. Lett., 39, L09806, https://doi.org/10.1029/2012GL051851, 2012b.

Fan, J., Leung, L. R., Rosenfeld, D., Chen, Q., Li, Z., Zhang, J., and Yan, H.: Microphysical effects determine macrophysical response for aerosol impacts on deep convective clouds, P. Natl. Acad. Sci. USA, 110, E4581-E4590, 2013.

Fan, J., Leung, L. R., DeMott, P. J., Comstock, J. M., Singh, B., Rosenfeld, D., Tomlinson, J. M., White, A., Prather, K. A., Minnis, P., Ayers, J. K., and Min, Q.: Aerosol impacts on California winter clouds and precipitation during CalWater 2011: local pollution versus long-range transported dust, Atmos. Chem. Phys., 14, 81-101, https://doi.org/10.5194/acp-14-81-2014, 2014.

Fan, J., Wang, Y., Rosenfeld, D., and Liu, X.: Review of aerosolcloud interactions: mechanisms, significance, and challenges, $\mathrm{J}$. Atmos. Sci., 73, 4221-4252, 2016.

Folkins, I.: Origin of lapse rate changes in the upper tropical troposphere, J. Atmos. Sci., 59, 992-1005, 2002.

Fovell, R. G. and Ogura, Y.: Numerical simulation of a midlatitude squall line in two dimensions, J. Atmos. Sci., 45, 3846-3879, 1988.

Frederick, K. L.: Anvil characteristics as seen by C-POL during the Tropical Warm Pool International Cloud Experiment (TWP-ICE) (Doctoral dissertation, Texas AandM University), 2006.

Futyan, J. M. and Del Genio, A. D.: Deep convective system evolution over Africa and the tropical Atlantic, J. Climate, 20, 50415060, 2007.

Gallagher, M. W., Connolly, P. J., Crawford, I., Heymsfield, A., Bower, K. N., Choularton, T. W., Allen, G., Flynn, M. J., Vaughan, G., and Hacker, J.: Observations and modelling of microphysical variability, aggregation and sedimentation in tropical anvil cirrus outflow regions, Atmos. Chem. Phys., 12, 6609 6628, https://doi.org/10.5194/acp-12-6609-2012, 2012.

Gong, W., Min, Q., Li, R., Teller, A., Joseph, E., and Morris, V.: Detailed cloud resolving model simulations of the impacts of Saha- ran air layer dust on tropical deep convection - Part 1: Dust acts as ice nuclei, Atmos. Chem. Phys. Discuss., 10, 12907-12952, https://doi.org/10.5194/acpd-10-12907-2010, 2010.

Grant, L. D. and van den Heever, S. C.: Cold pool and precipitation responses to aerosol loading: Modulation by dry layers, J. Atmos. Sci., 72, 1398-1408, 2015.

Hallgren, R. E. and Hosler, C. L.: Preliminary results on the aggregation of ice crystals, in: Physics of Precipitation: Proceedings of the Cloud Physics Conference, Woods Hole, Massachusetts, June 3-5, 1959, 257-263, American Geophysical Union, 1960.

Heymsfield, A. J., Bansemer, A., Field, P. R., Durden, S. L., Stith, J. L., Dye, J. E., and Grainger, C. A.: Observations and parameterizations of particle size distributions in deep tropical cirrus and stratiform precipitating clouds: Results from in situ observations in TRMM field campaigns, J. Atmos. Sci., 59, 3457-3491, 2002.

Hiron, T. and Flossmann, A. I.: A study of the role of the parameterization of heterogeneous ice nucleation for the modelling of microphysics and precipitation of a convective cloud, J. Atmos. Sci., 72, 3322-3339, https://doi.org/10.1175/JAS-D-15-0026.1, 2015.

Kain, J. S.: The Kain-Fritsch convective parameterization: an update, J. Appl. Meteorol., 43, 170-181, 2004.

Karyampudi, V. M. and Carlson, T. N.: Analysis and numerical simulations of the Saharan air layer and its effect on easterly wave disturbances, J. Atmos. Sci., 45, 3102-3136, 1988.

Karydis, V. A., Kumar, P., Barahona, D., Sokolik, I. N., and Nenes, A.: Assessing the Impact of Mineral Dust and Adsorption Activation on Cloud Droplet Formation, in: Advances in Meteorology, Climatology and Atmospheric Physics, 515-520, Springer Berlin Heidelberg, 2013.

Khain, A. P.: Notes on state-of-the-art investigations of aerosol effects on precipitation: a critical review, Environ. Res. Lett., 4, 015004, https://doi.org/10.1088/1748-9326/4/1/015004, 2009.

Khain, A. and Pokrovsky, A.: Simulation of effects of atmospheric aerosols on deep turbulent convective clouds using a spectral microphysics mixed-phase cumulus cloud model Part II: Sensitivity study, J. Atmos. Sci., 61, 2983-3001, 2004.

Khain, A., Pokrovsky, A., Pinsky, M., Seifert, A., and Phillips, V.: Simulation of effects of atmospheric aerosols on deep turbulent convective clouds using a spectral microphysics mixed-phase cumulus cloud model, Part I: Model description and possible applications, J. Atmos. Sci., 61, 2963-2982, 2004.

Khain, A., Rosenfeld, D., and Pokrovsky, A.: Aerosol impact on the dynamics and microphysics of deep convective clouds, Q. J. Roy. Meteor. Soc., 131, 2639-2663, 2005.

Khain, A. P., BenMoshe, N., and Pokrovsky, A.: Factors determining the impact of aerosols on surface precipitation from clouds: An attempt at classification, J. Atmos. Sci., 65, 1721-1748, 2008.

Khain, A. P., Leung, L. R., Lynn, B., and Ghan, S.: Effects of aerosols on the dynamics and microphysics of squall lines simulated by spectral bin and bulk parameterization schemes, J. Geophys. Res.-Atmos., 114, D22203, https://doi.org/10.1029/2009JD011902, 2009.

Koop, T., Luo, B., Tsias, A., and Peter, T.: Water activity as the determinant for homogeneous ice nucleation in aqueous solutions, Nature, 406, 611-614, 2000.

Koren, I., Kaufman, Y. J., Rosenfeld, D., Remer, L. A., and Rudich, Y.: Aerosol invigoration and restructuring of At- 
lantic convective clouds, Geophys. Res. Lett., 32, L14828, https://doi.org/10.1029/2005GL023187, 2005.

Koren, I., Feingold, G., and Remer, L. A.: The invigoration of deep convective clouds over the Atlantic: aerosol effect, meteorology or retrieval artifact?, Atmos. Chem. Phys., 10, 8855-8872, https://doi.org/10.5194/acp-10-8855-2010, 2010a.

Koren, I., Remer, L. A., Altaratz, O., Martins, J. V., and Davidi, A.: Aerosol-induced changes of convective cloud anvils produce strong climate warming, Atmos. Chem. Phys., 10, 5001-5010, https://doi.org/10.5194/acp-10-5001-2010, 2010b.

Koren, I., Altaratz, O., and Dagan, G.: Aerosol effect on the mobility of cloud droplets, Environ. Res. Lett., 10, 104011, https://doi.org/10.1088/1748-9326/10/10/104011, 2015.

Kumar, P., Sokolik, I. N., and Nenes, A.: Measurements of cloud condensation nuclei activity and droplet activation kinetics of fresh unprocessed regional dust samples and minerals, Atmos. Chem. Phys., 11, 3527-3541, https://doi.org/10.5194/acp-113527-2011, 2011.

Lau, W. K., Kim, K. M., Hsu, C. N., and Holben, B. N.: Possible influences of air pollution, dust and sandstorms on the Indian monsoon, available at: https://public.wmo.int/en/bulletin/possibleinfluences-air-pollution-dust-and-sandstorms-indian-monsoon (last access: 6 August 2018), 2010.

Lawson, R. P., Jensen, E., Mitchell, D. L., Baker, B., Mo, Q., and Pilson, B.: Microphysical and radiative properties of tropical clouds investigated in TC4 and NAMMA, J. Geophys. Res.Atmos., 115, D00J08, https://doi.org/10.1029/2009JD013017, 2010.

Lawson, R. P., Woods, S., and Morrison, H.: The Microphysics of Ice and Precipitation Development in Tropical Cumulus Clouds, J. Atmos. Sci., 72, 2429-2445, https://doi.org/10.1175/JAS-D14-0274.1, 2015.

Lebo, Z. J. and Seinfeld, J. H.: Theoretical basis for convective invigoration due to increased aerosol concentration, Atmos. Chem. Phys., 11, 5407-5429, https://doi.org/10.5194/acp11-5407-2011, 2011.

Lebo, Z. J., Morrison, H., and Seinfeld, J. H.: Are simulated aerosolinduced effects on deep convective clouds strongly dependent on saturation adjustment?, Atmos. Chem. Phys., 12, 9941-9964, https://doi.org/10.5194/acp-12-9941-2012, 2012.

Lee, S. S., Donner, L. J., Phillips, V. T., and Ming, Y.: The dependence of aerosol effects on clouds and precipitation on cloud-system organization, shear and stability, J. Geophys. Res.Atmos., 113, https://doi.org/10.1029/2007JD009224, 2008.

Lee, S. S., Donner, L. J., and Penner, J. E.: Thunderstorm and stratocumulus: how does their contrasting morphology affect their interactions with aerosols?, Atmos. Chem. Phys., 10, 6819-6837, https://doi.org/10.5194/acp-10-6819-2010, 2010.

Lerach, D. G., Gaudet, B. J., and Cotton, W. R.: Idealized simulations of aerosol influences on tornadogenesis, Geophys. Res. Lett., 35, L23806, https://doi.org/10.1029/2008GL035617, 2008.

Li, R. and Min, Q. L.: Impacts of mineral dust on the vertical structure of precipitation, J. Geophys. Res.-Atmos., 115, D09203, https://doi.org/10.1029/2009JD011925, 2010.

Li, R., Min, Q. L., and Harrison, L. C.: A case study: the indirect aerosol effects of mineral dust on warm clouds, J. Atmos. Sci., 67, 805-816, 2010.
Li, Z., Niu, F., Fan, J., Liu, Y., Rosenfeld, D., and Ding, Y.: Longterm impacts of aerosols on the vertical development of clouds and precipitation, Nat. Geosci., 4, 888-894, 2011.

Lim, K. S. S., Hong, S. Y., Yum, S. S., Dudhia, J., and Klemp, J. B.: Aerosol effects on the development of a supercell storm in a double-moment bulk-cloud microphysics scheme, J. Geophys. Res.-Atmos., 116, D02204, https://doi.org/10.1029/2010JD014128, 2011.

Lohmann, U.: Possible aerosol effects on ice clouds via contact nucleation, J. Atmos. Sci., 59, 647-656, 2002.

May, P. T., Bringi, V. N., and Thurai, M.: Do we observe aerosol impacts on DSDs in strongly forced tropical thunderstorms?, J. Atmos. Sci., 68, 1902-1910, 2011.

Meyers, M. P., DeMott, P. J., and Cotton, W. R.: New primary icenucleation parameterizations in an explicit cloud model, J. Appl. Meteorol., 31, 708-721, 1992.

Min, Q. and Li, R.: Longwave indirect effect of mineral dusts on ice clouds, Atmos. Chem. Phys., 10, 7753-7761, https://doi.org/10.5194/acp-10-7753-2010, 2010.

Min, Q.-L., Li, R., Lin, B., Joseph, E., Wang, S., Hu, Y., Morris, V., and Chang, F.: Evidence of mineral dust altering cloud microphysics and precipitation, Atmos. Chem. Phys., 9, 3223-3231, https://doi.org/10.5194/acp-9-3223-2009, 2009.

Min, Q. L., Li, R., Lin, B., Joseph, E., Morris, V., Hu, Y., and Wang, S.: Impacts of mineral dust on ice clouds in tropical deep convection systems, Atmos. Res., 143, 64-72, 2014.

Mlawer, E. J., Taubman, S. J., Brown, P. D., Iacono, M. J., and Clough, S. A.: Radiative transfer for inhomogeneous atmospheres: RRTM, a validated correlated-k model for the longwave, J. Geophys. Res.-Atmos., 102, 16663-16682, 1997.

Möhler, O., Stetzer, O., Schaefers, S., Linke, C., Schnaiter, M., Tiede, R., Saathoff, H., Krämer, M., Mangold, A., Budz, P., Zink, P., Schreiner, J., Mauersberger, K., Haag, W., Kärcher, B., and Schurath, U.: Experimental investigation of homogeneous freezing of sulphuric acid particles in the aerosol chamber AIDA, Atmos. Chem. Phys., 3, 211-223, https://doi.org/10.5194/acp-3211-2003, 2003.

Morris, V., Clemente-Colón, P., Nalli, N. R., Joseph, E., Armstrong, R. A., Detrés, Y., and Lumpkin, R.: Measuring trans-Atlantic aerosol transport from Africa, Eos, Transactions American Geophysical Union, 87, 565-571, 2006.

Morrison, H.: On the robustness of aerosol effects on an idealized supercell storm simulated with a cloud systemresolving model, Atmos. Chem. Phys., 12, 7689-7705, https://doi.org/10.5194/acp-12-7689-2012, 2012.

Muhlbauer, A. and Lohmann, U.: Sensitivity studies of aerosolcloud interactions in mixed-phase orographic precipitation, J. Atmos. Sci., 66, 2517-2538, 2009.

Mullendore, G. L., Durran, D. R., and Holton, J. R.: Cross-tropopause tracer transport in midlatitude convection, J. Geophys. Res.-Atmos., 110, D06113, https://doi.org/10.1029/2004JD005059, 2005.

Nakanishi, M. and Niino, H.: An improved Mellor-Yamada level-3 model: Its numerical stability and application to a regional prediction of advection fog, Bound.-Lay. Meteorol., 119, 397-407, 2006.

National Centers for Environmental Prediction/National Weather Service/NOAA/U.S. Department of Commerce: NCEP FNL Operational Model Global Tropospheric Analyses, continu- 
ing from July 1999, Research Data Archive at the National Center for Atmospheric Research, Computational and Information Systems Laboratory, Boulder, Colorado, available at: https://doi.org/10.5065/D6M043C6 (last access: 2 August 2018), 2000.

Niemand, M., Möhler, O., Vogel, B., Vogel, H., Hoose, C., Connolly, P., and Leisner, T.: A particle-surface-area-based parameterization of immersion freezing on desert dust particles, J. Atmos. Sci., 69, 3077-3092, 2012.

Niu, F. and Li, Z.: Systematic variations of cloud top temperature and precipitation rate with aerosols over the global tropics, Atmos. Chem. Phys., 12, 8491-8498, https://doi.org/10.5194/acp12-8491-2012, 2012.

O'Dowd, C. D., Smith, M. H., Consterdine, I. E., and Lowe, J. A.: Marine aerosol, sea-salt, and the marine sulphur cycle: A short review, Atmos. Environ., 31, 73-80, 1997.

Prospero, J. M.: Long-term measurements of the transport of African mineral dust to the southeastern United States: Implications for regional air quality, J. Geophys. Res.-Atmos., 104, 15917-15927, 1999.

Prospero, J. M. and Carlson, T. N.: Radon-222 in the North Atlantic trade winds: Its relationship to dust transport from Africa, Science, 167, 974-977, 1970.

Pruppacher, H. R. and Klett, J. D.: Microphysics of Clouds and Precipitation: With an Introduction to Cloud Chemistry and Cloud Electricity, 954 pp., 1997.

Ren, C. and MacKenzie, A. R.: Cirrus parametrization and the role of ice nuclei, Q. J. Roy. Meteor. Soc., 131, 1585-1605, 2005.

Rosenfeld, D., Lohmann, U., Raga, G. B., Dowd, C. D., Kulmala, M., Fuzzi, S., Reissell, A., Andreae, M. O.: Flood or drought: How do aerosols affect precipitation? Science, 321, 1309-1313, https://doi.org/10.1126/science.1160606, 2008.

Rosenfeld, D., Wood, R., Donner, L. J., and Sherwood, S. C.: Aerosol cloud-mediated radiative forcing: highly uncertain and opposite effects from shallow and deep clouds, in: Climate Science for Serving Society, 105-149, Springer Netherlands, 2013.

Ryzhkov, A., Pinsky, M., Pokrovsky, A., and Khain, A.: Polarimetric radar observation operator for a cloud model with spectral microphysics, J. Appl. Meteorol. Climatol., 50, 873-894, 2011.

Saleeby, S. M., Heever, S. C., Marinescu, P. J., Kreidenweis, S. M., and DeMott, P. J.: Aerosol effects on the anvil characteristics of mesoscale convective systems, J. Geophys. Res.-Atmos., 121, 10880-10901, https://doi.org/10.1002/2016JD025082, 2016.

Sassen, K., DeMott, P. J., Prospero, J. M., and Poellot, M. R.: Saharan dust storms and indirect aerosol effects on clouds: CRYSTAL-FACE results, Geophys. Res. Lett., 30, 1633, https://doi.org/10.1029/2003GL017371, 2003.

Skamarock, W. C., Klemp, J. B., Dudhia, J., Gill, D. O., Barker, D. M., Duda, M. G., Huang, X.-Y., Wang, W., and Powers, J. G.: WRF-ARW Model: A Description of the Advanced Research WRF Version 3, https://doi.org/10.5065/D68S4MVH, 2008.

Smirnova, T. G., Brown, J. M., and Benjamin, S. G.: Performance of different soil model configurations in simulating ground surface temperature and surface fluxes, Mon. Weather Rev., 125, 18701884, 1997.

Smith, P. L.: Equivalent radar reflectivity factors for snow and ice particles, J. Clim. Appl. Meteorol., 23, 1258-1260, 1984.

Solomon, S., Qin, D., Manning, M., Alley, R. B., Berntsen, T., Bindoff, N. L., and Wratt, D.: Technical summary, available at: https: //www.ipcc.ch/pdf/assessment-report/ar4/wg1/ar4-wg1-ts.pdf (last access: 6 August 2018), 2007.

Stith, J. L., Dye, J. E., Bansemer, A., Heymsfield, A. J., Grainger, C. A., Petersen, W. A., and Cifelli, R.: Microphysical observations of tropical clouds, J. Appl. Meteorol., 41, 97-117, 2002.

Storer, R. L. and Van den Heever, S. C.: Microphysical processes evident in aerosol forcing of tropical deep convective clouds, J. Atmos. Sci., 70, 430-446, 2013.

Storer, R. L., Van Den Heever, S. C., and Stephens, G. L.: Modeling aerosol impacts on convective storms in different environments, J. Atmos. Sci., 67, 3904-3915, 2010.

Storer, R. L., Heever, S. C., and L'Ecuyer, T. S.: Observations of aerosol-induced convective invigoration in the tropical east Atlantic, J. Geophys. Res.-Atmos., 119, 3963-3975, 2014.

Tao, W.-K., Li, X., Khain, A., Matsui, T., Lang, S., and Simpson, J.: Role of atmospheric aerosol concentration on deep convective precipitation: Cloud-resolving model simulations, J. Geophys. Res., 112, D24S18, https://doi.org/10.1029/2007JD008728, 2007.

Tao, W. K., Chen, J. P., Li, Z., Wang, C., and Zhang, C.: Impact of aerosols on convective clouds and precipitation, Rev. Geophys., 50, RG2001, https://doi.org/10.1029/2011RG000369, 2012.

Thompson, G., Field, P. R., Rasmussen, R. M., and Hall, W. D.: Explicit forecasts of winter precipitation using an improved bulk microphysics scheme. Part II: implementation of a new snow parameterization, Mon. Weather Rev., 136, 5095-5115, https://doi.org/10.1175/2008MWR2387.1.2008, 2008.

Twohy, C. H., Kreidenweis, S. M., Eidhammer, T., Browell, E. V., Heymsfield, A. J., Bansemer, A. R., and Van Den Heever, S. C.: Saharan dust particles nucleate droplets in eastern Atlantic clouds, Geophys. Res. Lett., 36, L01807, https://doi.org/10.1029/2008GL035846, 2009.

Vali, G.: Nucleation terminology, B. Am. Meteor. Soc., 66, 14261427, 1985.

Vali, G., DeMott, P. J., Möhler, O., and Whale, T. F.: Technical Note: A proposal for ice nucleation terminology, Atmos. Chem. Phys., 15, 10263-10270, https://doi.org/10.5194/acp-15-102632015, 2015.

van den Heever, S. C., Carrió, G. G., Cotton, W. R., DeMott, P. J., and Prenni, A. J.: Impacts of nucleating aerosol on Florida storms, Part I: Mesoscale simulations, J. Atmos. Sci., 63, 17521775, 2006.

Yin, Y., Carslaw, K. S., and Feingold, G.: Vertical transport and processing of aerosols in a mixed-phase convective cloud and the feedback on cloud development, Q. J. Roy. Meteoro. Soc., 131, 221-245, 2005.

Yoon, Y. J., Ceburnis, D., Cavalli, F., Jourdan, O., Putaud, J. P., Facchini, M. C., and O'Dowd, C. D.: Seasonal characteristics of the physicochemical properties of North Atlantic marine atmospheric aerosols, J. Geophys. Res.-Atmos., 112, D04206, https://doi.org/10.1029/2005JD007044, 2007.

Young, K. C.: A numerical simulation of wintertime, orographic precipitation: Part I, Description of model microphysics and numerical techniques, J. Atmos. Sci., 31, 1735-1748, 1974.

Zhang, D. and Anthes, R. A.: A high-resolution model of the planetary boundary layer-sensitivity tests and comparisons with SESAME-79 data, J. Appl. Meteorol., 21, 1594-1609, 1982.

Zhang, H., McFarquhar, G. M., Cotton, W. R., and Deng, Y.: Direct and indirect impacts of Saharan dust acting as cloud condensa- 
tion nuclei on tropical cyclone eyewall development, Geophys. Res. Lett., 36, L06802, https://doi.org/10.1029/2009GL037276, 2009.
Zhang, R., Li, G., Fan, J., Wu, D. L., and Molina, M. J.: Intensification of Pacific storm track linked to Asian pollution, P. Natl. Acad. Sci. USA, 104, 5295-5299, 2007. 